\title{
Supporting Collaborative Design Activity in a Multi-User Digital Design Ecology
}

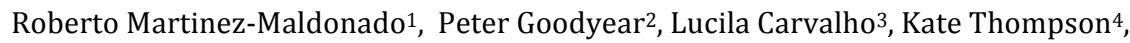 \\ Davinia Hernandez-Leo ${ }^{5}$, Yannis Dimitriadis ${ }^{6}$, Luis P. Prieto ${ }^{7}$ and Dewa Wardak ${ }^{8}$ \\ ${ }^{1}$ Connected Intelligence Centre, University of Technology Sydney, NSW 2008 (Australia), roberto.martinez-maldonado@uts.edu.au \\ ${ }^{2}$ Centre for Research on Learning and Innovation, The University of Sydney, NSW 2006 (Australia) \\ \{peter.goodyear,dewa.wardak\}@sydney.edu.au \\ ${ }^{3}$ Institute of Education, Massey University, Palmerston North 4474, (New Zealand), l.carvalho@massey.ac.nz \\ ${ }^{4}$ School of Education and Professional Studies, Griffith University, Brisbane, QLD 4122 (Australia), kate.thompson@griffith.edu.au \\ ${ }^{5}$ Serra Húnter, ICT Department, Universitat Pompeu Fabra, Barcelona, (Spain), davinia.hernandez@upf.edu \\ ${ }^{6}$ School of Telecommunications Engineering,University of Valladolid, Paseo Belén 15, 47011 Valladolid,(Spain), yannis@tel.uva.es \\ Center of Excellence in Educational Innovation,Tallinn University, Uus-Sadama 5, 10120 Tallinn, (Estonia), lprisan@tlu.ee
}

\begin{abstract}
Across a broad range of design professions, there has been extensive research on design practices and considerable progress in creating new computer-based systems that support design work. Our research is focused on educational/instructional design for students' learning. In this sub-field, progress has been more limited. In particular, neither research nor systems development have paid much attention to the fact that design is becoming a more collaborative endeavor. This paper reports the latest research outcomes from R\&D in the Educational Design Studio (EDS), a facility developed iteratively over four years to support and understand collaborative, real-time, co-present design work. The EDS serves to (i) enhance our scientific understanding of design processes and design cognition and (ii) provide insights into how designers' work can be improved through appropriate technological support. In the study presented here, we introduced a complex, multiuser, digital design tool into the existing ecology of tools and resources available in the EDS. We analysed the activity of four pairs of 'teacher-designers' during a design task. We identified different behaviors - in reconfiguring the task, the working methods and toolset usage. Our data provide new insights about the affordances of different digital and analogue design surfaces used in the Studio.
\end{abstract}

\section{Introduction and Background}

There has been extensive research and development work (R\&D) over the last few decades, studying and creating better support for practitioners in many design fields. The focus has shifted, steadily but slowly, from individual designers to collaborative design teams, within which complementary skills are brought together (Koutsabasis, Vosinakis, Malisova, \& Paparounas, 2012; McComb, Cagan, \& Kotovsky, 2015). The work reported in this paper contributes to a more specialised line of R\&D within educational technology, aimed at creating and testing better tools and methods for the design and production of learning resources. The sub-field of design to which we are contributing is variously described in the literature as instructional design, educational design, learning design, design for learning or teaching-as-design (Conole, 2013; Dalziel, 2015; Laurillard, 2012; McAndrew, Goodyear, \& Dalziel, 2006). More specifically, we are contributing to R\&D which, over the years, has included work on authoring languages and authoring systems (Barker, 1987), performance support for instructional design (Tennyson \& Barron, 2012), the language of instruction (Eckel, 1993), intelligent instructional design aids (Pirolli \& Russell, 1990), courseware engineering (Goodyear, 1995), educational modelling languages (Koper \& Tattersall, 2005), design patterns (Dimitriadis, 
Goodyear, \& Retalis, 2009), and visual languages for education (Botturi \& Stubbs, 2008). Pirolli (1991), Goodyear (1997), van Merriënboer \& Martens (2002) and Paquette (2013) provide reviews and a sense of the trajectory of this sub-field.

Conceptions of the nature of learning, the range of instructional approaches used, the tools and other resources available to learners, and the complexity of design problems have not stood still. Indeed, the problem space for educational design is now much more extensive and heterogeneous (Conole, 2013; Gibbons, 2013; Goodyear \& Dimitriadis, 2013). A good deal of the early work in this field concentrated on meeting the needs of 'solo' designers, such as subject-matter experts who had little or no pedagogical training. However, as in other design fields, collaborative design practice has become increasingly common, as the demand for richer, more complex learning experiences has increased at all educational levels. A distinctive feature of our collective approach is that we aim to study and improve the work of design teams, rather than solo designers, designing for complex learning situations, such as those involved in collaborative, open-ended, inquiry-based forms of learning (Lu, Lajoie, \& Wiseman, 2010; Strijbos, Kirschner, \& Martens, 2004). Support for collaborative educational design is still far from common, but some interesting examples are beginning to appear, such as LdShake (e.g. Hernández-Leo, Moreno, Chacón, \& Blat, 2014b) and SyncrLD (Derntl, Nicolaescu, Terkik, \& Klamma, 2013).

We built an Educational Design Studio (EDS) to carry out research on collaborative educational design. The design sessions studied in the EDS usually involve small $(2 \leq n \leq 6)$ teams consisting of university or school teachers, educational designers and/or educational technologists. The design sessions studied in the EDS typically last between one and four hours, and are usually one part of an extended design process that lasts for several weeks. The EDS has evolved through several cycles of development (Thompson, Ashe, Carvalho, Goodyear, Kelly, \& Parisio, 2013a; Wardak, 2014), each of which has typically involved: brainstorming and use of mock-ups by members of our research team; implementation of new tools and methods; user testing, and in-depth analysis of rich, multi-channel audio and video recordings of design teams in action. From this work, we have learned that it is essential to understand each new tool as just one part of a complex digital and material ecology of tools and resources which collectively constitute the EDS. We are also better able to depict the complex, evolving, interdependencies between tools, working methods and divisions of labour in the collaborative activity of design teams.

The main goal of this paper is to share results from the latest iteration of the EDS. This iteration involves the following new elements: i) high-level conceptual design tasks that encourage rapid consideration of alternative design options by a small team of designers; and ii) a set of personal and shared multitouch surface devices. The most significant new element is a prototype multitouch design table running software that we have produced to support rapid conceptual design through the provision of design patterns and other scaffolds for design work.

The remainder of the paper is structured as follows: in the next subsections (1.1 and 1.2), we provide a summary of recent R\&D relevant to the EDS: focussing on computer-based support for design and collaboration respectively. Section 2 explains the rationale for, and development of, the EDS and summarises the main lessons learned from earlier iterations of studying design activity in the EDS. Section 3 presents our new empirical material, analysing the incorporation of a multi-user digital design table into the existing ecology of tools of the Studio. We summarise data describing the distribution of activity of the teacher-designer participants and share the outcomes of closer examination of specific fragments of activity. The paper ends with section 4 which presents insights and more general implications for the support of collaborative educational design, as well as suggestions for future research in this area. 


\subsection{Computer-based support for (educational) design}

Most areas of design practice outside education rely upon a range of tools and methods in the conduct of their work. In design fields in which computer-aided analysis of the performance of designed components is possible, the use of CAD (computer-aided design) systems quickly became the norm (Li, Lu, Fuh, \& Wong, 2005; Mitchell, 1977). In architecture and product design, CAD systems are often linked to computer-aided manufacturing systems (CAD-CAM) so that design complexity and construction complexity can be managed together. In these more established design professions, formal notation systems and visual languages have also been developed and adopted, enabling partial or complete designs to be stored, shared and re-used.

While there has been some exploratory R\&D along these lines in education (see e.g. Botturi \& Stubbs, 2008; Koper \& Tattersall, 2005), the use of formal notation systems and visual languages is still rare in educational practice. A thin stream of empirical studies of the work of experienced (and novice) instructional designers, and of teachers engaged in specially-formulated design tasks, attests to the fact that designing for other people's learning is suffused with "wicked problems" which rapidly overpower the unaided design abilities of many education professionals (Ertmer, Stepich, York, Stickman, Wu, Zurek, \& Goktas, 2008; Huizinga, Handelzalts, Nieveen, \& Voogt, 2013; Kirschner, Carr, van Merriënboer, \& Sloep, 2002; Rowland, 1992; Tessmer \& Wedman, 1995).

A number of tools supporting the analysis phase of design have been proposed in the literature. Most of them are provided as document-based templates or descriptions of pedagogical ideas that can be completed or read with a computer or on pieces of printed paper. For example, the Persona Card and Similarly, Factors and Concerns templates can guide designers' reflections around intentional, social and material factors that describe the design context, situating the perspective of the learners in the centre of the design (Mor \& Mogilevsky, 2013). Course Features (Cross, Galley, Brasher, \& Weller, 2012) also supports the analysis phase, offering teachers a list of elements to help them decide which ones may be useful to consider in their designs. Design patterns can also support pedagogical decisions; they provide structured descriptions of sound pedagogical ideas that serve specific educational situations (Goodyear \& Retalis, 2010b).

The articulation of design ideas as overviews of courses and activities is also supported by a range of software tools. For instance, Course Map (Cross, et al., 2012) supports table-based textual outlines of courses. CompendiumLD (Brasher, Conole, Cross, Weller, Clark, \& White, 2008) provides a visual interface to represent maps of learning outcomes, sequences of activities and information about task times. Other design tools scaffold teachers in the authoring of detailed plans for learning activities, ready to be used in practice. One example is LDSE (Laurillard, Charlton, Craft, Dimakopoulos, Ljubojevic, Magoulas, Masterman, Pujadas, Whitley, \& Whittlestone, 2013) which embeds knowledge of pedagogical research to guide teachers in planning. Web Collage (VillasclarasFernández, Hernández-Leo, Asensio-Pérez, \& Dimitriadis, 2013) supports the design of learning tasks based on collaborative learning flow and assessment patterns that are provided to teachers as visual templates. OpenGLM (Derntl, Neumann, \& Oberhuemer, 2011) implements a more general visual representation (like a concept map) that allows the expression of diverse pedagogies.

Most computer-based educational design tools, such as those mentioned above, are desktop or Web-based editors that support a single user. They function in ways that limit their value to design teams - for example, some allow only one designer at a time to interact with the system. In contrast, the LdShake platform (Hernández-Leo, et al., 2014b) targets teams by enabling the sharing and coediting of learning designs. This platform has been extended with the integration of several analysis and design tools, providing an Integrated Learning Design Environment (ILDE) (Hernández-Leo, Asensio-Pérez, Derntl, Prieto, \& Chacón, 2014a). In ILDE, designers can work on analysis and design templates or authoring tools, and share their designs with other teachers. A similar example of work on tools to support collaborative educational design is the SyncLD web-based authoring system (Nicolaescu, Derntl, \& Klamma, 2013). A distinctive feature of SyncLD is that it offers synchronous co- 
editing of collaborative designs. Among the current challenges for research and development in this area are (i) supporting fluid interaction and (ii) helping members of a design team maintain mutual awareness (Nicolaescu et al., 2013).

\subsection{Interactive Surfaces for Small Group Collaboration}

Face-to-face communication still provides some benefits for collaboration in comparison with what can easily be achieved in computer-mediated, geographically-distributed group work (Olson, Teasley, Covi, \& Olson, 2002; Wineman, Hwang, Kabo, Owen-Smith, \& Davis, 2014). Nevertheless, some particular difficulties in coordinating collaborative face-to-face work have been reported when multiple people share a single personal device (Okdie, Guadagno, Bernieri, Geers, \& McLarneyVesotski, 2011). As a result, there has been a growing interest in moving from considering single devices to considering the ecologies of devices needed to support fluid interaction and mutual awareness in face-to-face collaborative work (Haller, Leitner, Seifried, Wallace, Scott, Richter, Brandl, Gokcezade, \& Hunter, 2010) and collaborative learning (Dillenbourg \& Evans, 2011; Vasiliou, Ioannou, \& Zaphiris, 2014). These emerging ecologies often feature interactivity among physical and digital objects and allow users to physically interact with digital surfaces while communicating faceto-face.

Within this line of R\&D, there has been a particular interest in the use of interconnected touchbased surfaces and mobile devices to create ecological niches for collaboration. Evans and Rick (2014) describe the following uses for interactive surfaces and spaces in learning settings: digital tables (interactive tabletops) have been used to support small-group, hands-on tasks in the classroom; tablets and mobile phones have been used to offer more sensitive touch capabilities and a private space for group members to perform individual tasks before sharing the outcomes with the group; and interactive whiteboards (IWB's) have been widely used in classrooms to support teachers' lecturing, and (less often) to support small group collaborations. Another study of small group collaboration has demonstrated the value of embedding multiple devices in the collaborative space (Haller, et al., 2010; Wigdor, Jiang, Forlines, Borkin, \& Shen, 2009). Group members can benefit from the advantages of each device and compensate for their limitations. For example, horizontal table displays can invite egalitarian participation but vertical shared displays can be better for visualising the whole artefact produced by a group or groups (Rogers, Lim, Hazlewood, \& Marshall, 2009). Similarly, combining tablets and tabletops to support group discussions may promote the use of gestures and touch across devices (Oleksik, Milic-Frayling, \& Jones, 2014) while maintaining situation and group awareness (Schmitt, Buisine, Chaboissier, Aoussat, \& Vernier, 2012). However, the use of an ecology of surfaces for team-based design work has not received much attention by researchers, and so even less is known about their use in design for learning.

\section{Approach and Rationale}

Evaluation studies of educational design tools in use, as cited above, provide some hints as to why the clear need for design support does not translate readily into the take-up of available tools. For example, significant problems emerge if there are mismatches between preferred ways of thinking about educational issues and the functionalities of the tools and formal representations made available (Prieto, Dimitriadis, Craft, Derntl, Émin, Katsamani, Laurillard, Masterman, Retalis, \& Villasclaras, 2013; Prieto, Tchounikine, Asensio-Pérez, Sobreira, \& Dimitriadis, 2014). There can also be mismatches in terms of the alignment between what tools do and the mix of expertise available in a design team. Also, when designers get experience with using new design tools, their understanding of what CAD can offer changes - they are better placed to help specify requirements for next generation tools. Finally, new tools can help prompt the invention of new design practices.

\subsection{The Activity-Centred Analysis and Design Framework}

Our research uses the Activity-Centred Analysis and Design (ACAD) Framework described by Carvalho and Goodyear (2014) as a way of understanding complex activities in which numerous 
tools, tasks and people combine. It helps achieve a realistically-grounded, holistic perspective on what people actually do in collaborative activity, and the tools, resources and social interactions that become bound up in that activity. Activity unfolds in ways that are both powerfully and subtlety shaped by the qualities of the working space - including the tools that come to hand - the people who are around, and the nature of the task being tackled. From a design viewpoint, these three components are referred as (1) set design - the physical/digital space(s) within which activity takes place; the tools, artefacts and other such resources that need to be available; (2) social design roles, group formation, divisions of labour, etc; and (3) epistemic design - the design of tasks, including the implicit and explicit knowledge elements bound up in the tasks (see Fig. 1, left). The ACAD framework also acknowledges that what is designed in advance will then be customised, selected from, added to, re-interpreted and otherwise modified by the people involved in the ensuing activity. This can be referred as (4) co-configuration of the situation (see Fig. 1, right) and aspects of the activity that result in new personal and/or collective knowledge - including knowledge inscribed in new artefacts - is referred to as co-creation (Goodyear \& Carvalho, 2014). Although the ACAD framework places activity at the centre, there are significant theoretical differences between ACAD and, what is known as, Activity Theory in how activity is defined. For Activity Theory, activity must be goal-oriented (see e.g. [Kaptelinin (2005)]). ACAD makes no such assumption, activity is simply what the learner actually did, whether goaloriented or not. What the learner actually does is consequential for learning outcomes, whether or not their activity is goal-oriented.

\section{Design time Ongoing activity}

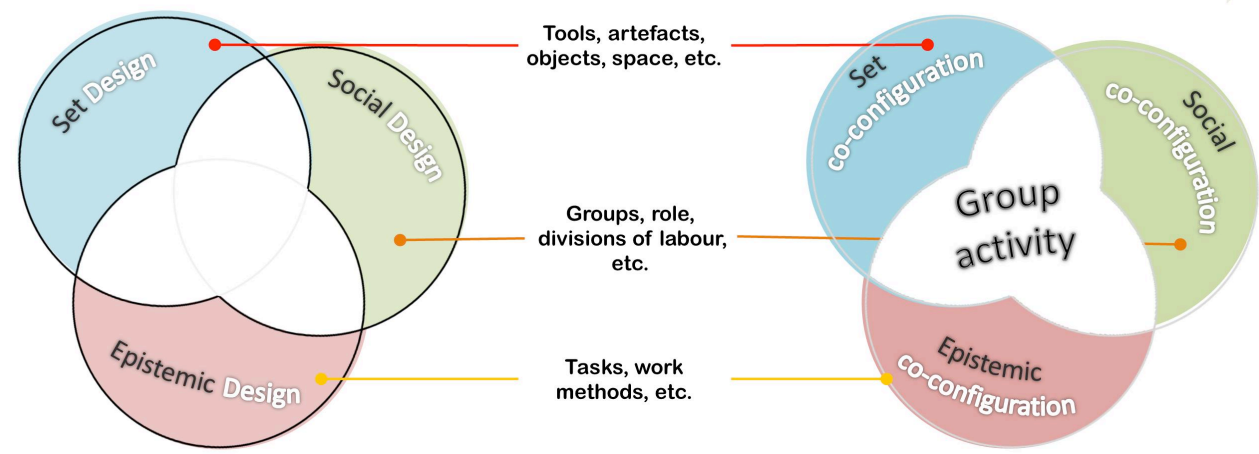

Fig. 1. Representation of the activity-centred analysis and design (ACAD) framework for group activity, derived from Goodyear and Carvalho (2014)

The ACAD framework is normally applied to the analysis and design of collaborative learning situations. These can involve, for example, the co-creation of group artefacts, or coming up with a solution to a set problem or other such learning task. Martinez-Maldonado et al. (2016) demonstrated how ACAD can serve as an effective middle-layer tool to help researchers and analysts to choose analytical tools that cover all the key dimensions of collaboration. In this paper, we apply it to help explain and understand the complexity of the activity that unfolds in the Educational Design Studio. That is, when we share data from our observations of design team activity in section 3 of the paper, we do so by reference to the tasks that the designers are tackling (epistemic), the ways they interact with each other and divide up the labour (social) and the ways they use the various tools, resources and surfaces in the Studio space (set). We additionally focus on the core educational design aspects that have evolved from the series of iterations of the Design Studio.

\subsection{The Educational Design Studio Physical Space}

The EDS is a physical space located at the University of Sydney. It is equipped with tools to support small groups engaged in design activities. It has built-in audio-visual recording infrastructure to 
capture research data related to designers in action (e.g. design discourse, drawing, gestures, expressions, outputs and so on). It also contains a number of tools, both digital and material, which can be used to facilitate the work of design. Fig. 2 shows the main working area in the studio, illustrating the movable and fixed features as well as some of the recording devices. The main elements labelled in Fig. 2 are: A) a variable number of video cameras and high-resolution time-lapse still image cameras that can be synchronised to allow multi-channel video analysis; B) two large displays connected to the screens of dedicated desktop computers or tablets; C) an Interactive Whiteboard (IWB); D) two large writeable walls; E) wireless mice and keyboards to control the computers connected to the large displays; F) a number of small, wireless microphones that can be worn by participants to capture what each says (not visible in the figure); and G) paper, pencils, coloured markers, etc.

The development of the EDS is best understood as part of an organic, incremental approach to the improvement of support for educational design teams. The evolution of the EDS is not only concerned with the physical space and the objects situated in it (shown above, in Fig. 2). It also includes other elements that emerge from the design or are re-configured in the ongoing team activities. These elements include, for example, the working methods, team dynamics, divisions of labour, use of design patterns, and use of the ecologies of devices. The current phase of our work, taking this approach, studies designers collaborating to visually represent their designs in the EDS. In this latest phase (to be described in section 3.3), we have introduced interactive surface technology, digital inter-connectivity between devices and the development of a design application based on design patterns. Fig. 3 pictures the evolution towards the latest version of the EDS. The multi-touch, multi-surface additions reported in this paper are a response to a number of trials carried out in the EDS during 2013-2014 - summarised in the next section. The new additions (2015-2016) have been fine-tuned and trialled in two steps: 1) workshops with expert users and 2) observations of small design teams using the new tools while working on some design tasks that we set them - reported in section 3.3. A preliminary version of the collaboration aspects of the observational studies (2) was presented in short in (Martinez-Maldonado, Goodyear, Dimitriadis, Thompson, Carvalho, Prieto, \& Parisio, 2015).

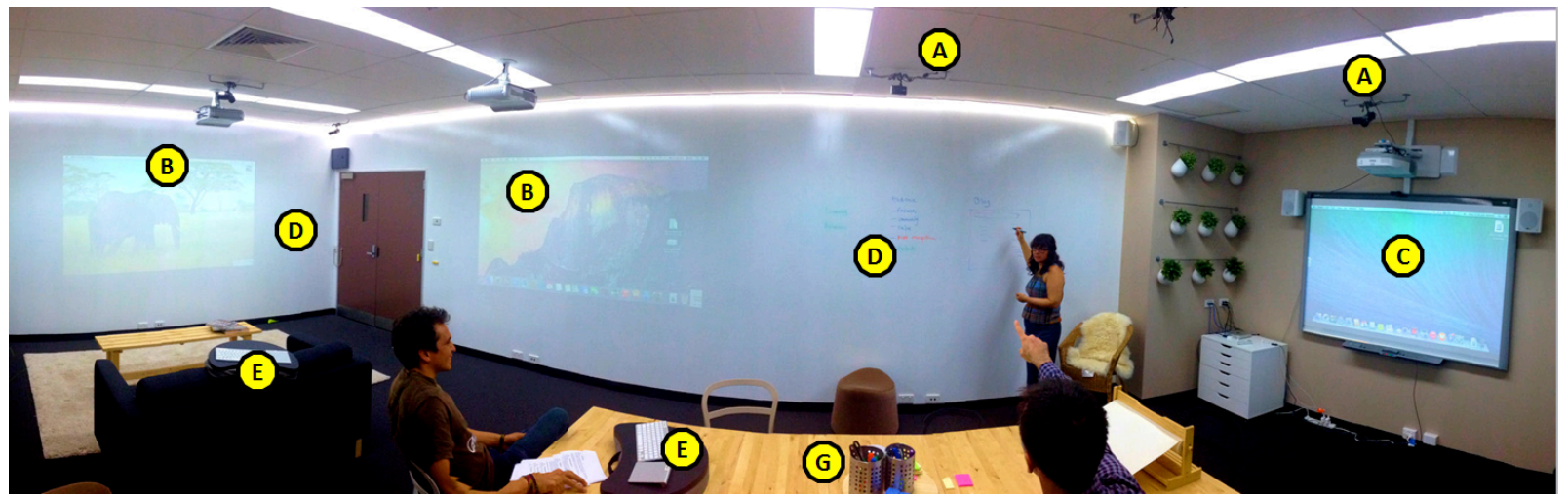

Fig. 2. Panoramic view of the Educational Design Studio representing how it is commonly used by small groups to discuss and build a design together, featuring: a) a number of recording devices, b) wall projectors, c) an IWB, d) writeable walls, e) wireless pointer devices, f) wearable microphones

(not visible in the image) and $g$ ) various writing materials

\subsection{Headline Findings from Earlier Trials in the Educational Design Studio}

Four sets of earlier studies have contributed to our understanding of how designers use the EDS. The first study (Thompson, et al., 2013a) followed a group of Masters-level student designers engaged in the creation of educational design patterns and a pattern language as part of an assignment. In the analysis of this study, we observed how roles were negotiated around the use of tools and the task requirements. We developed indicators that showed how after three meetings in the EDS, three 
group members created roles for themselves based on specialised use of tools (adding to the pattern language on the writeable wall, adding to the documentation, transferring the inscriptions to an online tool) in order to achieve an epistemic purpose (collating the group's ideas about the pattern language, relating the collaboratively produced artefact back to the original task outline, and translating the pattern language into the chosen tool).

In a second study, three groups of postgraduate level student-designers, designing an online learning resource for environmental education in schools, similarly negotiated their roles around the use of tools (set) (Thompson, Ashe, Wardak, Yeoman, \& Parisio, 2013b) as well as around task requirements (epistemic) (Thompson, Ashe, Yeoman, \& Parisio, 2013c). Analysis in this study showed how tool use becomes attached to specific epistemic activities (e.g. the whitewall was used for the development of ideas, whereas tablets were used for permanent recording of ideas). In one group, one student became responsible for recording the ideas, while all students participated in the development of ideas. A third study (Wardak, 2014) focused on observations of a group of professional designers who were designing a touch-based educational game for children aged 7-11, to run on smart phones and tablets. This study revealed a rich set of ways in which designers use hand-written inscriptions to communicate and make their design ideas tangible; and their use of gestures in creating and discussing those inscriptions. It also underlined the fact that rapid perception-action loops are key to fluent collaborative design processes - and that discourse, inscription and gesturing are tightly interwoven in group design work. These insights deepen our confidence that a promising direction for the EDS is to use multiple, large, writable, recordable, gesture-controlled surfaces to support a smoothly flowing group design process. A fourth study (Thompson, 2015) involved users designing an educational blog. This study explored the effects of three different design scaffolds on epistemic and social aspects of the activity as well as on the use of design tools and the physical space. Thus far, analyses have shown that the epistemic and social scaffolds resulted in productive design work and that, in particular, the epistemic scaffolds impacted on patterns of decision-making in the collaborative design work.

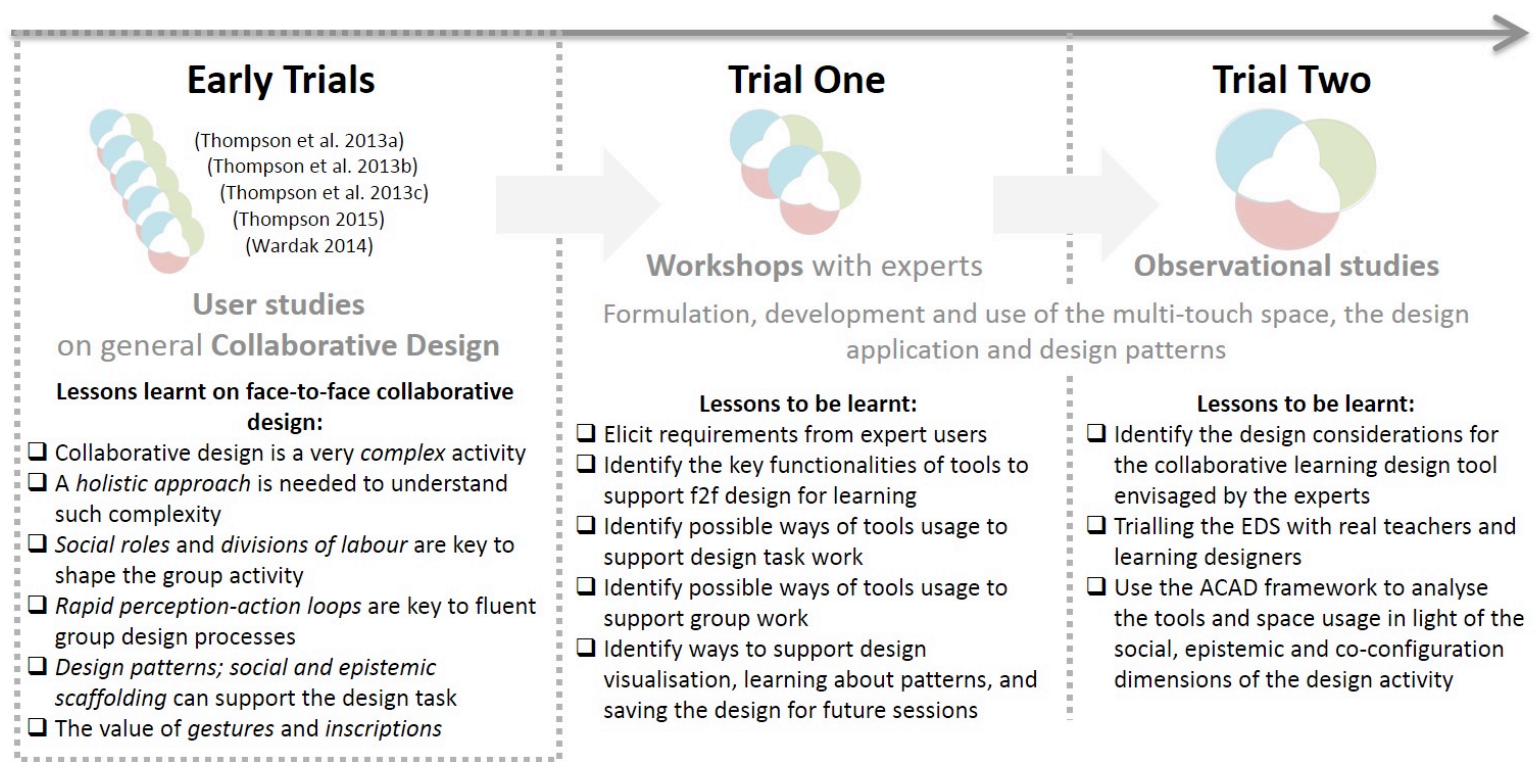

Fig. 3. Evolution of the Multi-Surface Educational Design Studio: early trials, with major findings described in section 2.3; trial one workshops with expert users, to be described in section 3.1 and the main observational studies, to be described in section 3.3.

These earlier trials allowed us to map some of the complexities of collaborative design, which is shaped not only by the tools and the space where it unfolds but also by the dynamic qualities of the working methods and social interactions that occur among designers. The ACAD framework has been used to understand this complex design activity as a whole. Design aids, such as the use of 
design patterns or the provision of social or epistemic scaffolding, can support collaborative design work, but success is dependent on a mix of factors. Providing opportunities for work that involves rapid perception-action loops, facilitated by the use of multiple tools, displays, design representations and gestures, can be particularly helpful in promoting fluid group design processes in face-to-face situations (see Fig. 3, left).

\section{User Experiences: Introducing the Multi-surface Technologies into the Studio}

\subsection{Trial One: Workshops with Expert Users}

In this step of the evolution of the EDS, we investigated users' perceptions of the functions offered by the tools available in the EDS. We conducted two workshops with expert users in the EDS in order to understand the collaborative design responsibilities these experts attributed to the tools and digital devices (see Fig. 3, centre). We use the term responsibilities (commonly used in software design) to refer to the way our expert users think about how the tools can "cover" or "become responsible for" or "have delegated to them" certain kinds of tasks or problems. These responsibilities can be intrinsic functionalities of the tool, ways the tool can be used to scaffold particular aspects of group work or ways in which tools may be used by designers in the actuality of their work. Six designers who had previously participated in experiments in the EDS took part in the workshops. These were structured as follows: 1 ) participants were presented with a scenario where a group of three users had the goal of visually representing the tasks in a semester-long course; 2 ) participants were asked to respond to open-ended questions and complete a questionnaire about the best uses of the tools and devices currently available in the EDS, and about new ones that might be introduced; and 3) participants were asked to identify what responsibilities would best be allocated to the tools (for the particular tasks and goals) in the scenario described.

Table 1 presents the results of the questionnaire data collected during these workshops. Participants discussed the introduction of a multi-user digital table to the EDS; ways to take advantage of the multitouch capabilities of the interactive whiteboard (IWB); and the usage of tablet devices, wall displays, writeable walls, and paper-based materials. The analysis identified two main groups of responsibilities which are linked to i) Task work (1-building, 2-sketching and 3-scaffolding the task), and ii) Group work (4-mutual awareness, 5-participation, 6-collaboration and 7-scaffolding social interaction). Additionally, other crucial responsibilities identified were to provide support for the visualisation of the whole course design (8), scaffolding the use of patterns to design (9), and ways to save the design for future re-use (10).

Table 1 Relationships between tools and responsibilities identified by six users with previous experience of R\&D work in the EDS

\begin{tabular}{|c|c|c|c|c|c|c|c|}
\hline & & \multicolumn{6}{|c|}{ Tools* } \\
\hline & Responsibilities & $\begin{array}{c}\text { Digital } \\
\text { Table }\end{array}$ & IWB & Tablets & Wall display & $\begin{array}{c}\text { Writeable } \\
\text { wall }\end{array}$ & $\begin{array}{c}\text { Pen and } \\
\text { paper }\end{array}$ \\
\hline \multirow{3}{*}{$\begin{array}{l}\text { Task } \\
\text { work }\end{array}$} & 1- Building the design & 4 & 3 & & 1 & 4 & 1 \\
\hline & 2- Sketching & & 1 & 1 & 1 & 6 & 5 \\
\hline & 3- Scaffolding the task & 4 & 2 & 4 & 3 & & 3 \\
\hline \multirow{4}{*}{$\begin{array}{l}\text { Group } \\
\text { work }\end{array}$} & 4- F2F mutual awareness & 4 & 3 & 2 & 2 & 3 & 1 \\
\hline & 5- Fair opportunities of participation & 4 & 1 & & 1 & 4 & \\
\hline & 6- Collaboration & 4 & 4 & & 1 & 4 & \\
\hline & 7- Scaffolding social interaction & 6 & 1 & 1 & 1 & & \\
\hline View & 8- Visualisation of the course design & 3 & 4 & & 4 & 1 & 1 \\
\hline Learn & 9- Learning about patterns & 2 & 3 & 4 & 4 & 1 & 1 \\
\hline Save & 10- Saving the design for future sessions & 4 & 4 & 4 & & 1 & 1 \\
\hline
\end{tabular}

Most participants indicated that the introduction of a digital table to the EDS for the proposed scenario could help designers in their hands-on activities and be beneficial to maintaining mutual awareness of each other's actions, creating opportunities for more equal participation in design 
work and promoting small-group collaboration (Table 1-column 1). Although similar responsibilities can also be associated with the use of the large writeable walls (Table 1, column 5), most

participants indicated that an advantage of a digital table is that it can be used to scaffold social and task-related aspects of group collaboration. For example, two users said that the multitouch devices can be used for "pre-programing instructions, roles or prompting users with best practices of design" or for "providing easy access to alternative digital tools, alternative representations or examples". This is also supported by previous empirical work in the area showing the potential of digital tables to positively influence performance and group work, depending on the task and tool design (Buisine, Besacier, Aoussat, \& Vernier, 2012).

By contrast, participants highlighted the role of sketching in design activities, indicating that nondigital tools (e.g. the writeable walls or paper) are still providing better support for hand-writing and free sketching (Table 1, row 2). Most large interactive surfaces currently available still impose challenges in relation to support for sketching (e.g. Badam, Chandrasegaran, Elmqvist, \& Ramani, 2014). The vertical displays (IWB and non-interactive displays, Table 1, columns 2 and 4 ) were considered the best options to help designers visualise the whole design. Participants indicated that personal devices, such as tablets (Table 1, column 3), could be used to scaffold the task, and would also help designers to quickly explore, in private, information about the subject matter, requirements, instructions, a pattern language, etc. Finally, participants valued the use of digital tools to provide continuity in the design work, for example, by allowing the re-use of designs and the preservation of design ideas from one session to another, "try multiple design candidates, or letting designers save and come back to previous versions of the same design" (row 10).

\subsection{Apparatus: The Multitouch Space, the Design Application and Design Patterns}

Combining the findings from the workshops with guidance from key literature in Educational Design and Human-Computer Interaction, we enhanced the EDS by adding new devices, software and interconnection between devices. The furniture, writable surfaces, digital tools etc. that were shown in Fig. 2 were reconfigured to allow the addition of (a) a digital table - placed on one side of the regular table; (b) a depth sensor located in the ceiling that enhances the digital table capabilities by identifying each of the users touching it (Martinez-Maldonado, Collins, Kay, \& Yacef, 2011); (c) a pair of tablet devices each connected to the wall projectors mirroring the tablet interfaces; and (d) a software application, called CoCoDes (Martinez-Maldonado \& Goodyear, 2016), running in parallel in the multitouch digital table and the IWB (see Fig. 4 and Fig. 5).

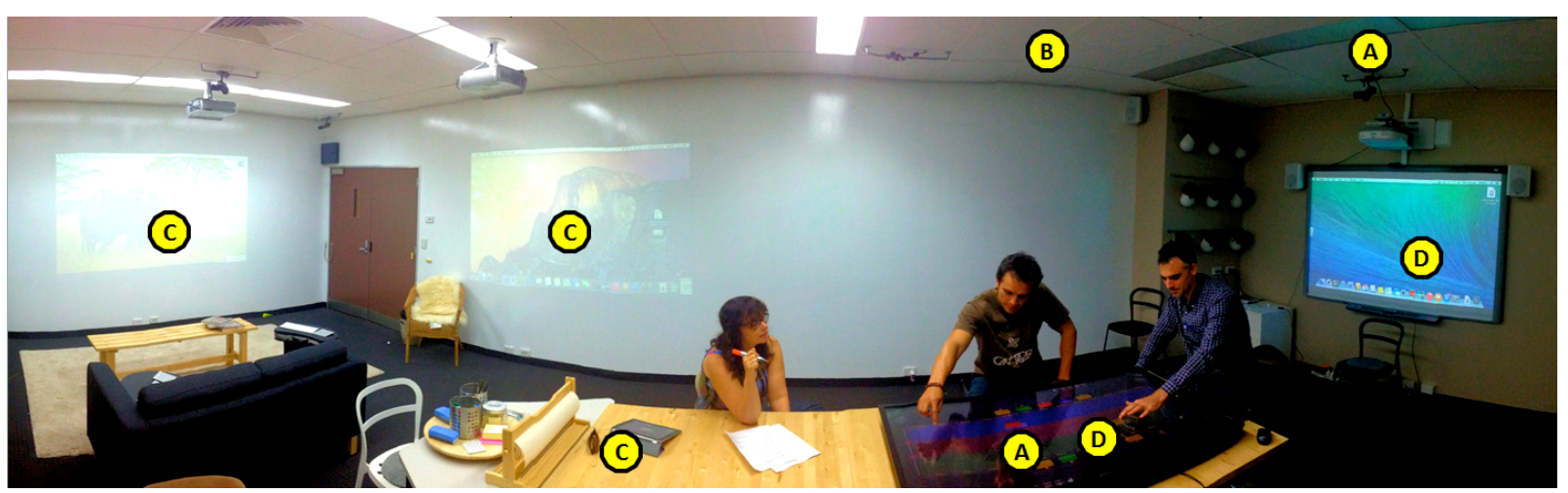

Fig. 4. Panoramic view of the Multi-surface Educational Design Studio featuring a) the multitouch digital table, b) a depth sensor, c) wall projectors, and d) the CoCoDes design-for-learning software

CoCoDes is a multitouch prototype application we developed that supports the collaborative design of a university course. It can be deployed on different devices (e.g. on the digital table and IWB, as in our studies). CoCoDes was purpose-built to meet the requirements of our experimental studies. Its design is grounded in rich knowledge of personal computer-based learning design tools (Derntl, et al., 2013; Hernández-Leo, et al., 2014b; Nicolaescu, et al., 2013; Prieto, et al., 2014), 
guidelines about collaboration around digital tables (Kharrufa, Martinez-Maldonado, Kay, \& Olivier, 2013; Müller-Tomfelde \& Fjeld, 2010; Scott, Grant, \& Mandryk, 2003) and the results of the Trial One workshops. The following design considerations informed the implementation of the tool (summarised in Table 2):

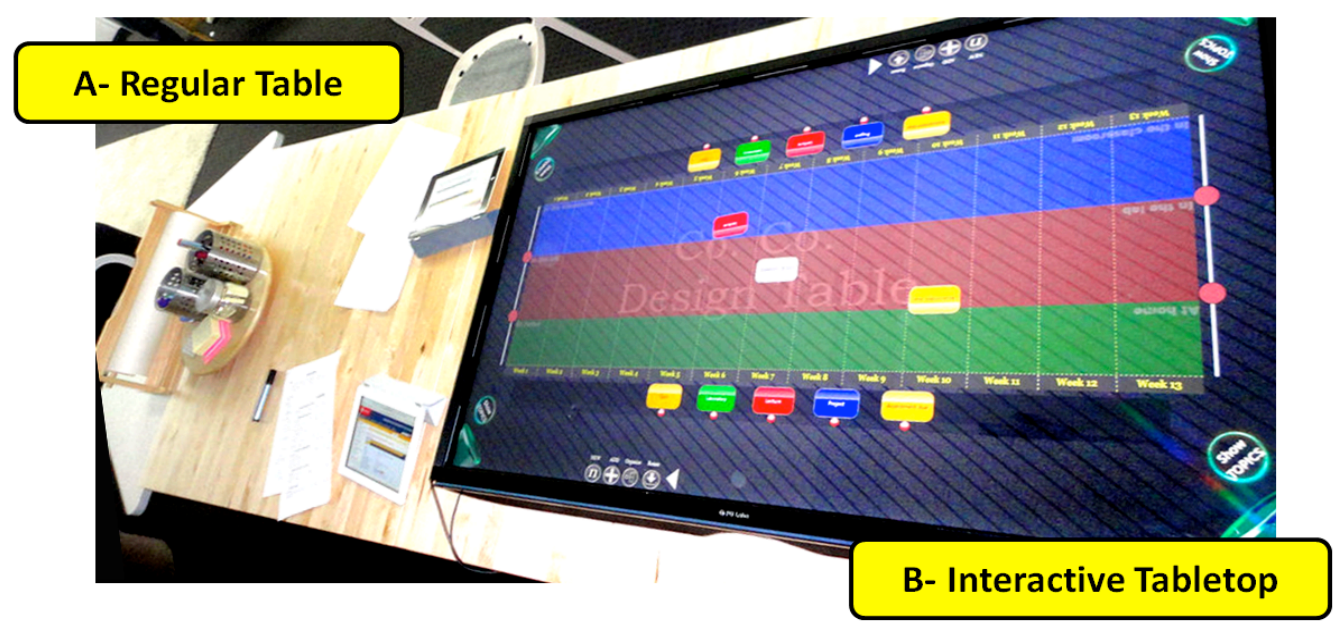

Fig. 5. Devices and physical objects placed on the large table at the centre of the Educational Design Studio at the start of each experiment: A- Paper-based instructions and pattern language, tablets, paper, markers, etc.; and B- the multiuser digital design table

1- Gestural interaction and mutual awareness. Studies conducted in the early trialling of the EDS showed that collaborators often maintained fluid communication using gestures and inscriptions (Wardak, 2014). Specifically, participants often used gestures in the air or touched non-interactive objects to support their arguments or point at relevant elements under discussion. Nicolaescu et al. (2013)'s preliminary work suggested that collaborative design for learning, performed online, can prevent teachers from knowing what the others are doing. Research on collaborative work has found that using a direct-touch interface in collaborative settings may not lead to greater performance in terms of speed and accuracy compared with using a mouse, however, it does provide enhanced sense making and awareness of the actions of others (Hornecker, Marshall, Dalton, \& Rogers, 2008). Implementation: The CoCoDes prototype provides gestural interaction elements that can be manipulated only by direct touch (rotatable draggables and touch buttons), allowing bimanual input and fluid interaction with the visual representations of the design (e.g. see Figures 5 and 6), making group members' actions visible and accountable.

2- Use of patterns and a pattern language. Design patterns can be used to address recurring problems within a given context by proposing re-usable solutions (Alexander, 1999). They have been used in architecture, manufacturing and software design. In learning scenarios, design patterns have the potential to make the connections between the design (or even theory) and teaching/learning practice more explicit (Diggelen \& Overdijk, 2009). However they have not yet enjoyed wide uptake in educational contexts (Hernández-Leo, Villasclaras-Fernández, Asensio-Pérez, \& Dimitriadis, 2007) even though some educational design tools have taken a patterns-based approach (e.g. Sobreira \& Tchounikine, 2012; Villasclaras-Fernández, et al., 2013). Nonetheless, it has been reported that teachers value educational design tools that provide re-usable elements, like templates (design patterns), and a vocabulary (a pattern language) that is familiar to them (Goodyear \& Retalis, 2010a; Prieto, et al., 2014). Implementation: In the prototype, a pattern language (PL) can be pre-loaded for teachers to use patterns as templates for students' tasks, learning spaces, or situations. Fig. 6 (topright) shows patterns (e.g. see the coloured squares labelled as Lecture, Laboratory, Group Formation etc.) that were positioned by designers by dragging pattern templates from a pattern catalogue. 
3- Workflows and learning spaces. In design for learning, patterns are often linked to notions of learning process or learning workflow. These workflows are physically and socially situated in certain spaces (e.g. the classroom or online virtual environments), with particular learning goals and requirements. Some existing desktop-based educational design tools provide ways to nest patterns along a timeline to represent sequential order (e.g. Villasclaras-Fernández, et al., 2013).

Implementation: In the CoCoDes prototype, the sequence of activities can be represented by the position of a given instance of a pattern in the user interface. A flipped-timeline is provided to visualise learning tasks on a weekly basis (see Fig. 5, the timeline goes from left to right). The interface also provides regions to associate learning tasks with learning spaces (e.g. blue, red and green horizontal bars in Fig. 5, for the classroom, laboratory and home spaces respectively). Inspired by the IMS-Learning Design specification (Britain, 2004), sub-workflows can be defined in parent instances (tasks) that can have various ordered child tasks, which in turn can also contain sub-tasks (e.g. see Fig. 6, bottom-right, a user creating a workflow for a task).
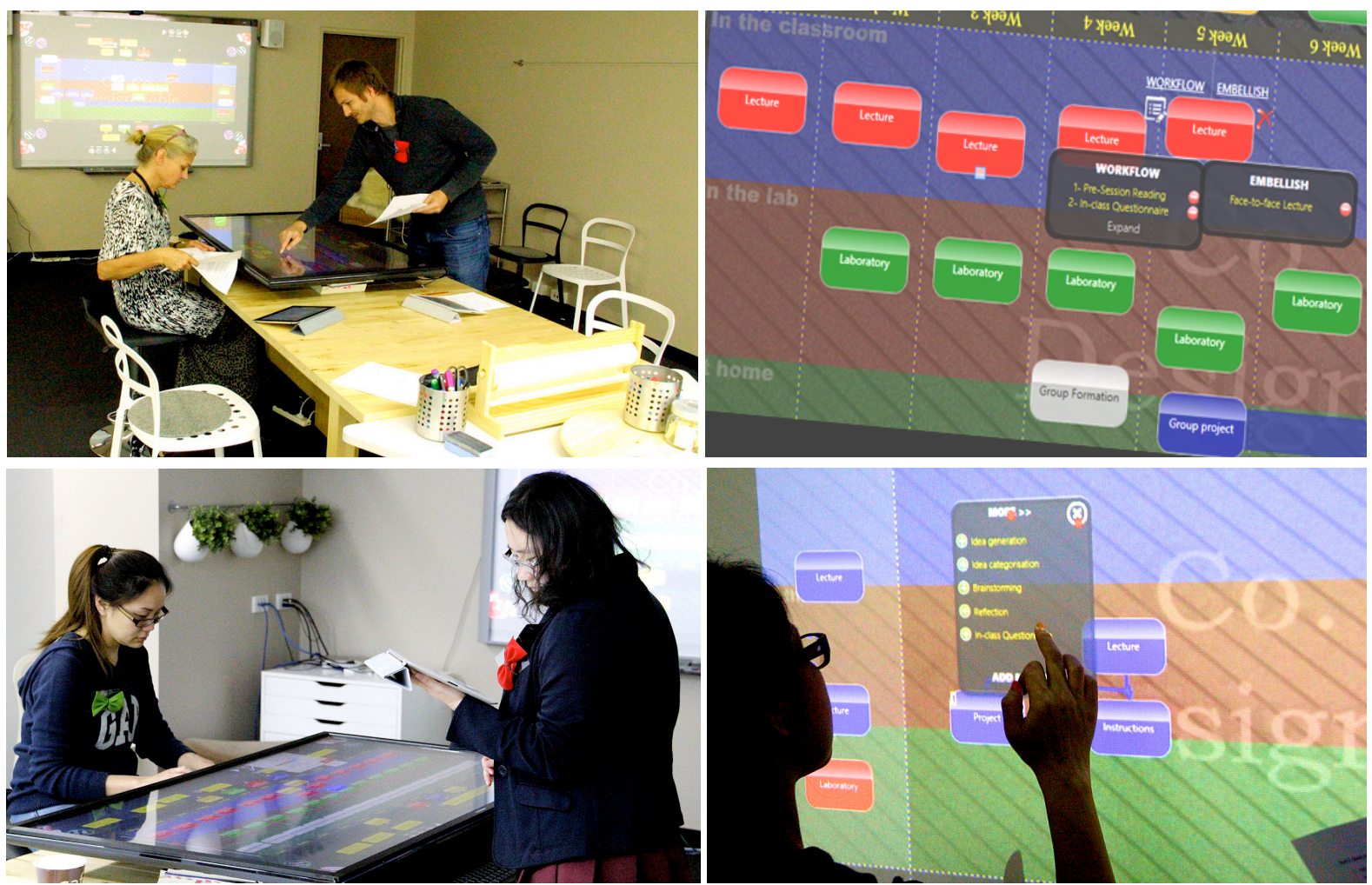

Fig. 6. The CoCoDes prototype displayed in the digital design table and IWB. Top-Left: participants face-to-face at the digital table. Top-Right: close-up of patterns placed on the semester view. Bottom -Left: one participant editing text and the other reading information from the tablet. Bottom-Right: participant defining the workflow of a pattern in the weekly view

4 - Different levels of detail (semester/week/task). Classic work on information visualisation by Shneiderman (1996) indicates that interfaces should present an overview of the information first, allowing users to zoom in and subsequently view details-on-demand. Implementation: Following this guideline, the CoCoDes prototype shows the design of the whole university course in the semester view (in the host university this is 13-14 weeks - see Fig. 5).Then, the designers can navigate to any specific weekly view to design or view details of what happens in that week. At a finer level still, the users can configure or see the details of the workflows within particular instances of patterns (e.g. see Fig. 6, bottom-right).

5- Scaffolding and flexibility to define learning goals/topics and patterns. As reported by Prieto et al. (2014), teachers say that tools for design for learning should provide scaffolding to support the construction of quick designs. For example, some design for learning tools help teachers to build a 
traceable link between learning goals, objectives and lower level tasks (Villasclaras-Fernández, et al., 2013). At the same time, users should be able to opt out - in order to follow the scripts or suggested patterns according to their task and social requirements at learntime (Prieto, et al., 2014).

Implementation: The CoCoDes prototype allows teachers to define their own ideas for patterns and to edit any pre-existing patterns. Multiple physical keyboards can be attached to allow faster input by multiple users. The prototype also provides a representation of learning topics or goals so the tasks can easily be linked with actual topics or goals as listed in the syllabus for the course.

Table 2 Design considerations for developing the CoCoDes prototype

\begin{tabular}{cll|l}
\multicolumn{1}{c|}{ Design consideration } & Technology implementation & \multicolumn{1}{c}{ Foundations } \\
\hline $\begin{array}{c}\text { 1- } \\
\text { Gestural interaction and mutual } \\
\text { awareness. }\end{array}$ & $\begin{array}{l}\text { Direct touch, rotatable draggables } \\
\text { and touch buttons }\end{array}$ & $\begin{array}{l}\text { Design Studio, Design for Learning, HCl } \\
\text { (Wardak 2014; Nicolaescu et al. 2013; } \\
\text { Hornecker et al. 2008) }\end{array}$ \\
\hline 2- & Use of patterns and a pattern language. & $\begin{array}{l}\text { Iconic representations of patterns } \\
\text { from a pattern catalogue. }\end{array}$ & $\begin{array}{l}\text { Design, Design for learning (Hernández-Leo } \\
\text { et al. 2007; Alexander 1999) }\end{array}$ \\
\hline 3- & Workflows and learning spaces. & $\begin{array}{l}\text { Semester timeline, tree-like sub } \\
\text { patterns structures }\end{array}$ & $\begin{array}{l}\text { Online Design for Learning (e.g. Villasclaras- } \\
\text { Fernández et al. 2013) }\end{array}$ \\
\hline 4- & $\begin{array}{l}\text { Different levels of detail } \\
\text { (semester/week/task). }\end{array}$ & $\begin{array}{l}\text { Semester view, weekly views, } \\
\text { expandable sub patterns }\end{array}$ & HCl, Design for Learning (Shneiderman 1996) \\
\hline 5- $\begin{array}{l}\text { Scaffolding and flexiblibility to define } \\
\text { learning goals/topics and patterns. }\end{array}$ & $\begin{array}{l}\text { Editable patterns, link with } \\
\text { curricula and learning goals }\end{array}$ & Design for Learning (Luis P Prieto et al. 2014) \\
\hline
\end{tabular}

\subsection{Trial Two: User Studies in the Multi-surface Educational Design Studio}

\subsubsection{Participants and trial design}

Building on the analysis of the early trialling and the workshops with expert users (reported above), we designed a new set of experiments in the multi-surface enriched EDS. The purpose was to (1) validate the design considerations for the collaborative learning design tool envisaged by the experts and (2) gain understanding about the tools and space usage in light of the social, epistemic and coconfiguration dimensions of the design activity (see Fig. 3, right). Four pairs of teacher-designers (six females and two males, average age of 35.7 years, SD 9) participated in the experiments. They all had teaching experience, varied learning design experience, and knew each other beforehand. The goal for participants was to produce the design of an actual course in the area of Engineering, held at The University of [hidden] (a 13-week course). The course, titled "Human-Computer Interaction", runs once each year and is commonly re-designed each year. One of the requirements was that the course design should include a variety of learning tasks that can create varied opportunities for learning for students enrolled in the course. High-level aspects of the course design include information relevant to the learning tasks - such as the learning spaces that will be used, task durations, student time distribution across the semester, modality of delivery (e.g. face-to-face or online), assessment strategies, deadlines, etc. More detailed aspects of the course design can also be defined, by including more specific information such as the workflow of tasks that students are intended to perform in each session, divisions of labour, group formation strategies, learning resources to be used, pedagogical strategies, etc. Design patterns can be used to define the highlevel as well as the detailed aspects of the course design. Participants in the study were asked to collaboratively design the high-level aspects of the full semester in the EDS. They were also asked to do the detailed design of learning tasks for at least two of the weeks (selected by the researchers, weeks 5 and 6).

The initial configuration of tools and space in the EDS was the same for all the sessions, as shown in Fig. 5. All participants were given the following paper materials: a task script (indicating the requirements and constraints of the course design); and a catalogue of patterns (a simple pattern language describing patterns relevant to such a course). Each participant was also provided with a tablet device that included: digital copies of the task script and the pattern language, and access to CUSP (an official online system that provides detailed descriptions of university courses - including 
topics, learning goals, teaching guidelines and a schedule for each course). The digital table and IWB were synchronised, so that any changes in either interface were immediately updated in both displays (see Fig. 6, top-left).

Before each experiment, we conducted an instructional session (30 minutes) during which participants were given a detailed explanation of the usage of the tablet devices, writeable walls, papers, physical materials and furniture, and also of the CoCoDes prototype. Next, participants had up to one hour to build their actual design (the groups' average time for this activity was 50 minutes, SD 2). After the collaborative design activity, a 20-minute semi-structured interview was conducted with each pair of designers. Then, each participant completed a questionnaire about their usage of the tools and space in the EDS. Each group was video recorded (groups A, B, C and D). Additionally, we manually recorded the time and duration of each participant's interaction with each tool and their location in the physical space in the EDS. We triangulated the quantitative information about tools and space usage, in relation to the task and social interaction, with qualitative data including the explanations by, and experiences of, the teacher-designers drawn from the questionnaires and interviews. The next subsections present the results of the analyses of tools and space usage and task achievement associated with the social, epistemic and co-configuration dimensions of the ACAD framework.

\subsubsection{Time data on tool usage}

An initial exploratory analysis was conducted to understand tool usage in the new configuration of the EDS. The duration of use of each of the tools was calculated, Figure 7 (right) shows the average time spent using each tool per person in each group.
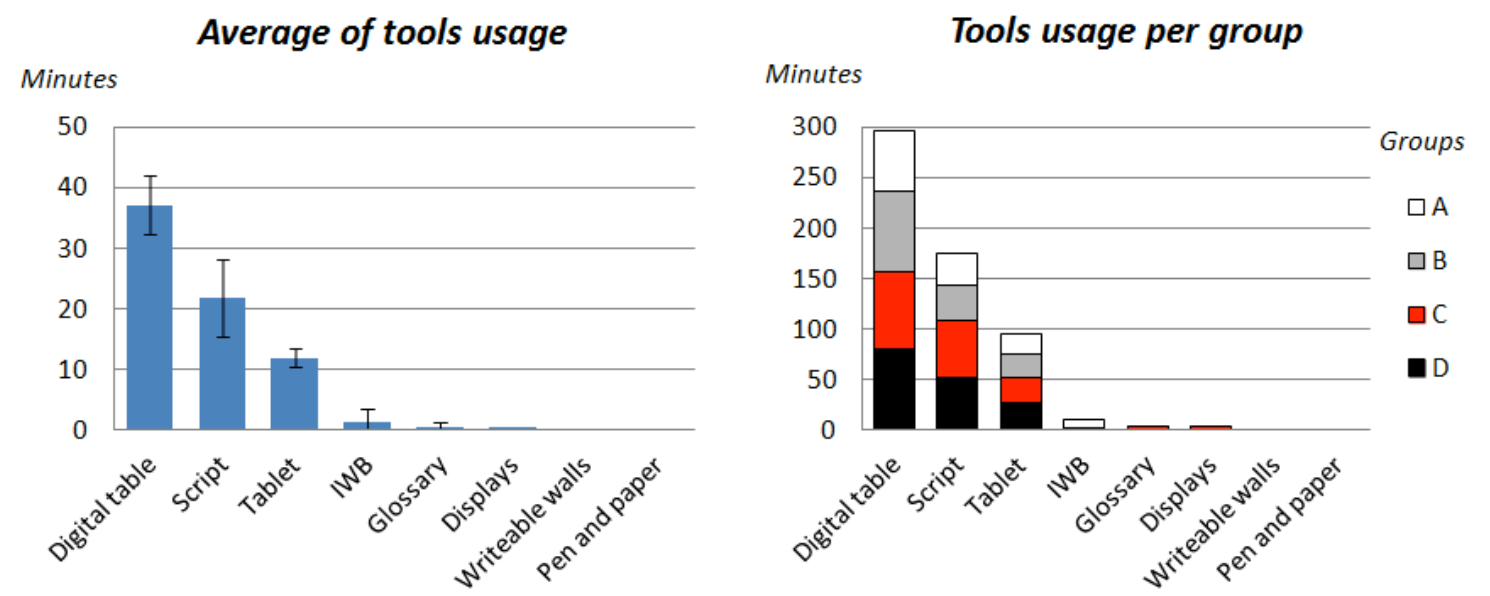

Fig. 7. Tool usage time per group. Left: average time of tool usage across all groups (more than one tool may be used by designers at the same time). Right: Tool usage per group.

The digital table was the most used tool, with participants spending an average of 37 minutes of the session interacting with it (SD 4.7) (see Figure 7, left). The other two most used tools were the paper-based task script and the tablet devices (22 minutes, SD 6.4, and 12 minutes, SD 1.5, per participant respectively). The other tools, including the IWB, the paper-based pattern language and the non-interactive displays mirrored with the tablets, were rarely used, and then only by one or two of the groups. Unlike studies in the earlier trials, in which the writeable walls were used extensively, in this trial, the non-digital tools, including the writeable walls and the paper and pencils located on the table, were never used (see section 3.3.7).

\subsubsection{Achievement of the design goals}

In terms of the quality of the produced designs, the duration of the user studies imposed an important constraint on the level of detail that the teacher-designers could achieve in their designs. 
This makes it difficult to directly measure the quality of the final designs, as these were not yet deployed in a full semester experience to conduct learning activities with regular students. Nevertheless, we analysed the degree of achievement of the design goals that were set to participants for the studies. As described above, the overall design goal for the teacher-designers was to build a design of the tasks planned for the $\mathrm{HCl}$ course that will be delivered to the tutors and lecturers that will enact that unit.

Participants were asked to complete at least four sub-goals: 1- Design the overall semester layout. This included mapping all the lectures and laboratories according to a set of pedagogical criteria mostly documented in the CUSP, such as the configuration of the duration of the learning activities, the days of the week when these would occur, and the modality in which they would be delivered. In order to do this, participants needed to, for example, decide which weeks' traditional lectures could be replaced by online lectures or by when groups would need to be assigned so that students could work on a project for the rest of the semester. 2-Configure the Project, Group formation, and Assessment patterns. This referred to the pedagogical decision-making around three key learning tasks (patterns). This required detailed design, for example, identifying milestones that students had to achieve during the semester, such as the generation of Prototypes, Reports and a Presentation of results. 3- Configure Week 5 in detail. This included the configuration of workflow sub-tasks for the laboratory and lecture sessions for that specific week. For example, Fig. 8 shows how Group B configured a series of sub-tasks for the laboratory in Week 5, including Idea generation, Idea categorisation, a Concept mapping task and reflection time at the end of the laboratory. 4- Configure Week 6 in detail. As with the previous goal, different workflow sub-patterns were requested to be configured for the main tasks in this week.

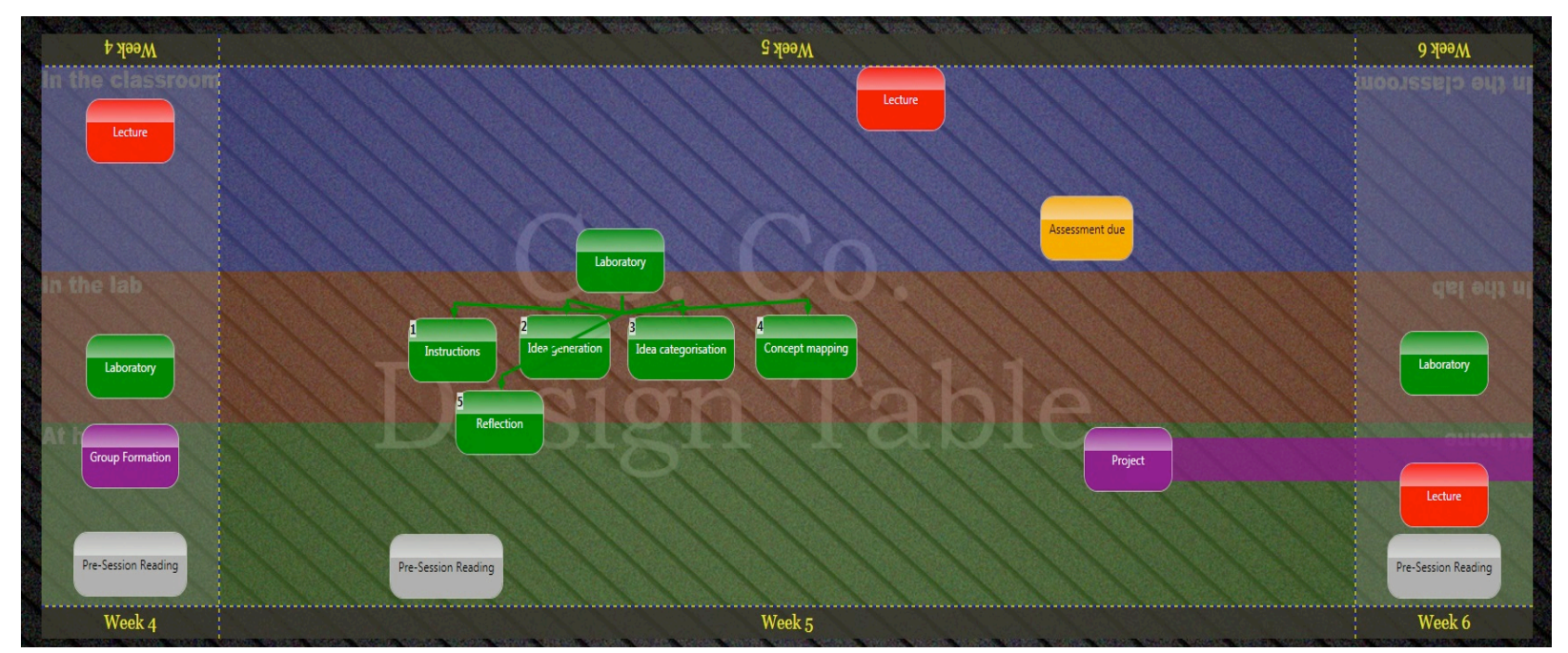

Fig. 8. Final outcome for the design of the learning tasks for Week 5 by Group B.

Table 3 shows the results of the analysis of the achievement of the design goals listed above. All groups achieved the first goal, they used a similar number of patterns in their learning designs (see row $i$ ) and configured the workflows for selected learning tasks (see row ii). Notably, members of Group A built the largest course design using a total of 103 patterns. For the second set of design goals, all groups used a small number of patterns (less than 7) to configure the semester project (iii), assessment due dates (iv), and the essential group formation (iv) for the course. Row vi presents the average number of patterns used in each week, excluding Weeks 5 and 6 . This helps to compare the degree of detail that participants achieved in their design of Weeks 5 and 6 . All four groups completed a more detailed design of the learning tasks for Week 5, both in terms of the number of patterns used and also the workflows defined in such a week (rows vii and viii respectively). Only groups A and D finalised a detailed design for Week 6 (see columns B and C, rows ix and $x$ respectively). In terms of completeness of the final designs, Groups B and C did not finish the design 
task in the allocated time. This indicates that the working methods linked to the tools usage reported in the previous sections, for these two groups, did not lead to the full achievement of all design goals.

Table 3 Achievement of the assigned design tasks by each group of designers

\begin{tabular}{|c|c|c|c|c|c|}
\hline \multirow{2}{*}{$\begin{array}{c}\text { Design } \\
\text { Task }\end{array}$} & \multirow{2}{*}{ Metric } & \multicolumn{4}{|c|}{ Groups } \\
\hline & & $\mathbf{A}$ & B & C & D \\
\hline \multirow{2}{*}{1} & i) Patterns in the final design & 103 & 67 & 70 & 85 \\
\hline & ii) Workflow sub-patterns & 58 & 29 & 41 & 37 \\
\hline \multirow{3}{*}{2} & iii) Instances used to model the PROJECT pattern & 4 & 4 & 4 & 1 \\
\hline & iv) Instances used to model the ASSESSMENT pattern & 2 & 1 & 1 & 1 \\
\hline & v) Instances used to model the GROUP FORMATION patern & 6 & 3 & 2 & 5 \\
\hline \multirow{3}{*}{3} & vi) Average number of patterns used in each week ${ }^{*}$ & $7.5 \pm 3$ & $4.7 \pm 1$ & $4.8 \pm 1$ & $5.5 \pm 1$ \\
\hline & vii) Patterns used in Week 5 & 11 & 11 & 14 & 13 \\
\hline & viii) Workflow sub-patterns in Week 5 & 7 & 7 & 12 & 9 \\
\hline \multirow{2}{*}{4} & ix) Patterns used in Week 6 & 10 & 4 & 4 & 13 \\
\hline & x) Workflow sub-patterns in Week 6 & 6 & 1 & 2 & 8 \\
\hline
\end{tabular}

\subsubsection{Tools used in combination}

The four groups mostly used the digital table, the tablets and the paper-based materials, in combination, to achieve the design goals (see Table 4). However, each participant used the tools in varied ways, often using multiple tools together. One participant explained that "using the tablet and the digital table at the same time was a really good resource in terms of looking at the schedule, teaching requirements and assessment of the [course]" that they were designing. The interaction time for when two or more tools were being used at the same time was analysed, and the results presented below.
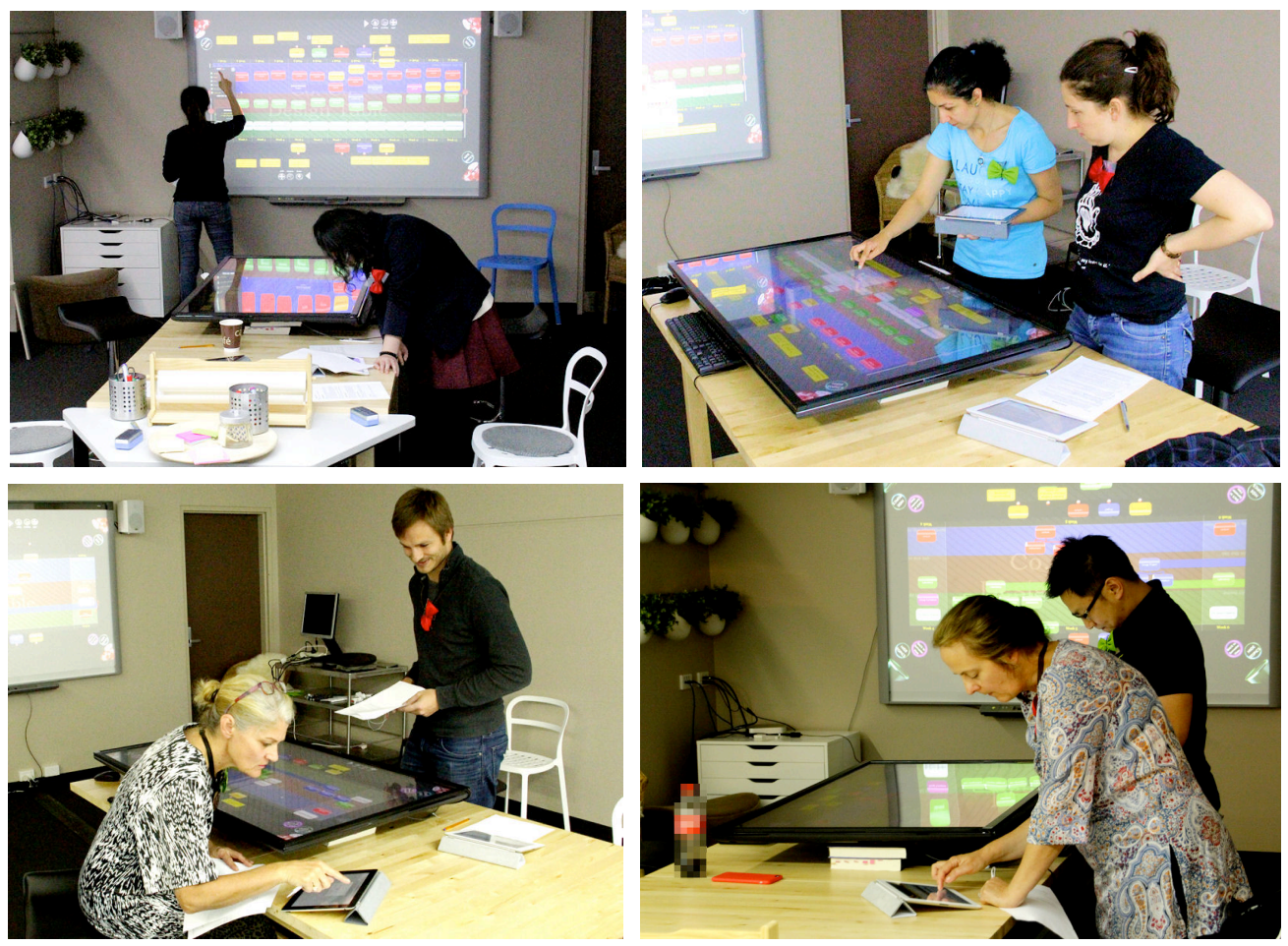

Fig. 9. The four groups using tools and space in varied ways. Top-left: Group A. Top-right: Group B. Bottom-left: Group C. Bottom-right: Group D

Participants spent an average of $61 \%$ (SD 11) of the total time using tools in each session interacting with more than one tool, either jointly or by holding one tool in each hand. The tools that 
were most frequently used in combination were: the digital table and the paper-based task script (average of $34.6 \%$, SD 17, of the tools usage time by each group); the digital table and a tablet (e.g. see all groups in Fig. 9, 17.8\%, SD 4); a tablet and the paper-based task script (average of 5\%, SD 1, of tools usage time by each group); and the IWB and the paper-based task script (average of $4.4 \%$, SD 7 , of tools usage time by each group). Further results are presented in Table 4.

Table 4 Tools used in combination and ratio of the total tools usage time by each group.

\begin{tabular}{|c|c|c|c|c|}
\hline \multicolumn{2}{|c|}{ Tools used in combination } & \multicolumn{2}{|c|}{$\%$ of the tools usage time by each group } & \multirow{2}{*}{$\begin{array}{l}\text { Groups } \\
\text { The four groups }\end{array}$} \\
\hline Digital table & Paper script & AVG 34.6 & SD 17 & \\
\hline Digital table & Tablet & AVG 17.8 & SD 4 & The four groups \\
\hline Paper script & Tablet & AVG 5.0 & SD 1 & The four groups \\
\hline IWB & Paper script & AVG 4.4 & SD 7 & Groups A and B \\
\hline Paper pattern language & Paper script & 1.9 & & Group C only \\
\hline Paper pattern language & Tablet & 0.4 & & Group C only \\
\hline Paper pattern language & Digital table & 0.3 & & Group C only \\
\hline IWB & Digital table & 0.3 & & Group B only \\
\hline Vertical display & Paper script & 0.1 & & Group D only \\
\hline
\end{tabular}

According to the literature, depending on personal choice, users of design tools deployed in personal computers adopt a cognitive representation of the type of information and its relationships presented in different windows or screens (Norman, Weldon, \& Shneiderman, 1986). While it can be convenient for a solo user to have everything in one system, in the case of collaborative work, having all the information and tools distributed across persistent displays and/or other physical objects is highly valuable. Shifting gaze from one screen or object to another is much faster than negotiating (within the group) about which information or tools should be in view on a shared display. Thus, the availability of multiple surface displays is important because rapid shifts of gaze are natural in human perception. This ability is often taken for granted and goes unnoticed until there is a hiatus in the flow of the work. However, it is time-consuming to negotiate over and switch between different tools, displays and so on. Table 4 shows that Groups B and C (neither of which completed the design task) used many tools in combination, whereas Groups $A$ and $D$, used a smaller set of tools in conjunction.

\subsubsection{Relationship between tools and design task}

Regarding the relationship between the use of the digital tool and the way groups tackled the task, we analysed how participants grasped the notion of patterns, if they looked at the catalogue of patterns and how they used the pattern instances. According to the questionnaire responses, most designers found it easy to understand and useful to work with patterns in the CoCoDes application. One designer explained that "being able to directly drag generic tasks [template patterns] into the timeline helped define and refine the design". Seven of the eight remaining teacher-designers strongly agreed that the patterns allowed them to effectively configure the course design.

However, only one group (Group C) actually looked at the paper-based glossary of tasks (the pattern language) to learn more about the details of selected patterns, and none of the groups accessed the digital copy of the pattern language available in the tablet devices. Part of the task given to the designers consisted of replacing a set of selected lectures held on the university campus with online lectures. Only group $C$ tried to understand the implications of this design decision: in particular, the pedagogical elements that might be lost in the change. One of the designers of this group said that "the [pattern language] helped them understand the trade-offs of substituting online for real-time [face-to-face] learning activities". This is the type of design thinking that we aim to support through the CoCoDes tool in further iterations. However, it only emerged in one of the four groups for this particular task and set design. Further scaffolding and/or sharper task-definition may be needed to encourage teacher-designers to engage more deeply in this aspect of design thinking. 
3.3.6 Relationship between tools/space and social interactions.

Regarding the different social interactions and the usage of the physical space of the EDS, the four groups behaved differently and, in some cases, re-arranged the pre-configured furniture.

Participants mostly worked around the digital table (77.8\% of the total activity time - see Fig. 5-B), and the rest of the time at the regular table (Fig. 5-A) and the IWB $(19.4 \%$ and $2.7 \%$ of the time respectively).
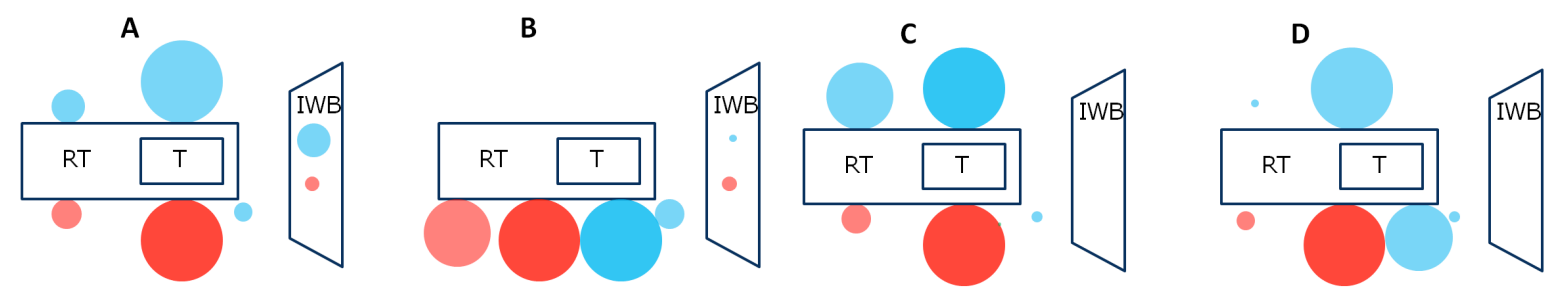

Fig. 10. Heatmaps of space usage for groups $(A, B, C$ and $D)$ : the size of each circle represents the amount of time each group member (represented with blue/clear or red/dark circles) spent in that

position in the design studio. RT= Regular table; T=Digital table; IWB=Interactive whiteboard

Heatmaps in Fig. 10 illustrate how the four groups used the space in very different ways. Groups $A$ and $C$ worked mostly face-to-face ( $f 2 f$ ) at the digital table but also at the regular table (see Fig. 10 $A$ and $C$ ). In fact, the use of space by group A reflected the division of labour they adopted. This group worked almost separately, without maintaining awareness of each other's actions. They worked in different spaces at different times (this is illustrated in Fig. 9, top-left, which shows the participants dividing labour and interacting with different shared devices). A contrasting strategy was followed by group B who worked side-by-side (SxS) (see Fig. 9, top-right and diagram corresponding to group B in Fig. 10). A third variant was observed in group D, where designers mostly interacted at the digital table but combined moments of F2F and SxS work (see Fig. 10, D). This positioning has implications for both the readability of the text on the table and for eye contact between the designers. Overall, different ways of working - F2F or SxS - were observed ( $29 \%$ and $30 \%$ of the time for F2F and SxS work among groups). The rest of the time designers worked in different spaces (e.g. one at the digital table and the other at the regular table).

\subsubsection{Tools and space usage}

Regarding the relationship between tool usage and participants' movements around the EDS, we observed two contrasting behaviours: 1) holding or bringing the tablet device or paper-based materials onto the digital table area, and 2) leaving the tablet or papers on the regular table and moving to that space when it was necessary to look at that information. Fig. 11 illustrates these two types of behaviour involving designers from the same group. A teacher-designer justified her preference for holding the tablet or papers while working at the digital table as follows: "it was good to have some space on both sides of the table so we could place the tablet next to it for quickly looking or for grabbing it".
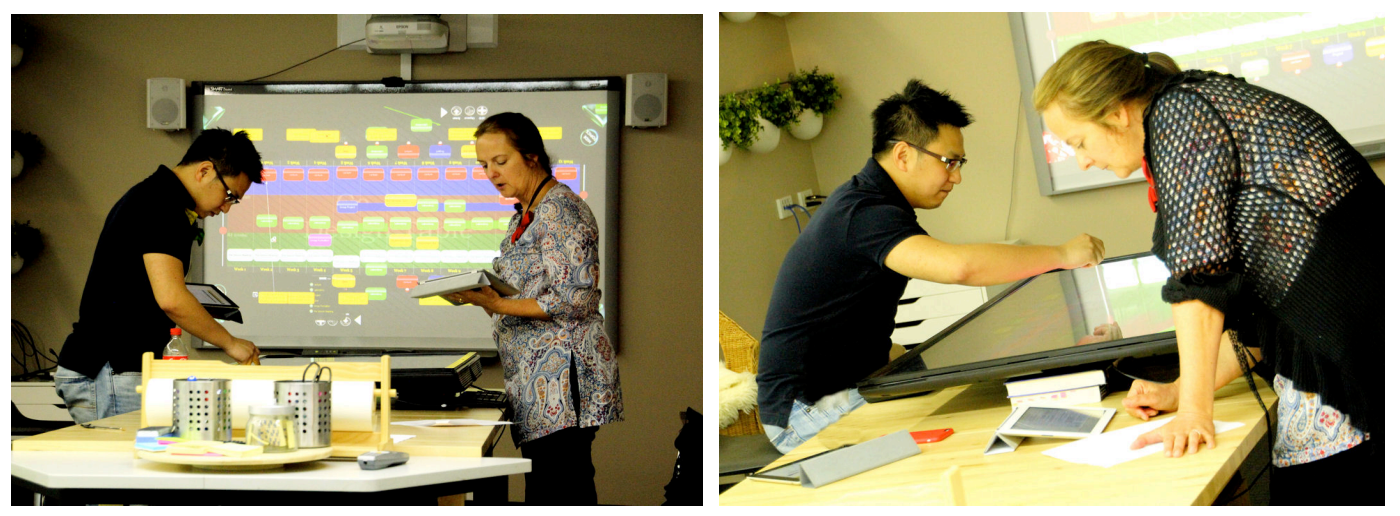
Fig. 11. Behaviours involving tool usage and participant movement around the physical space: 1) holding or bringing the tablet device or paper-based materials onto the digital table area, and 2) leaving the tablet or papers on the regular table and moving to that space when needed

Transitions between other tools and surfaces in the EDS were more infrequent. The IWB was used only by groups A and B. For example, Fig. 12 shows how these two groups used the IWB in two different ways: to split the work between the digital table and the IWB (left) or just as a vertical display to have an overview of the whole design (right).
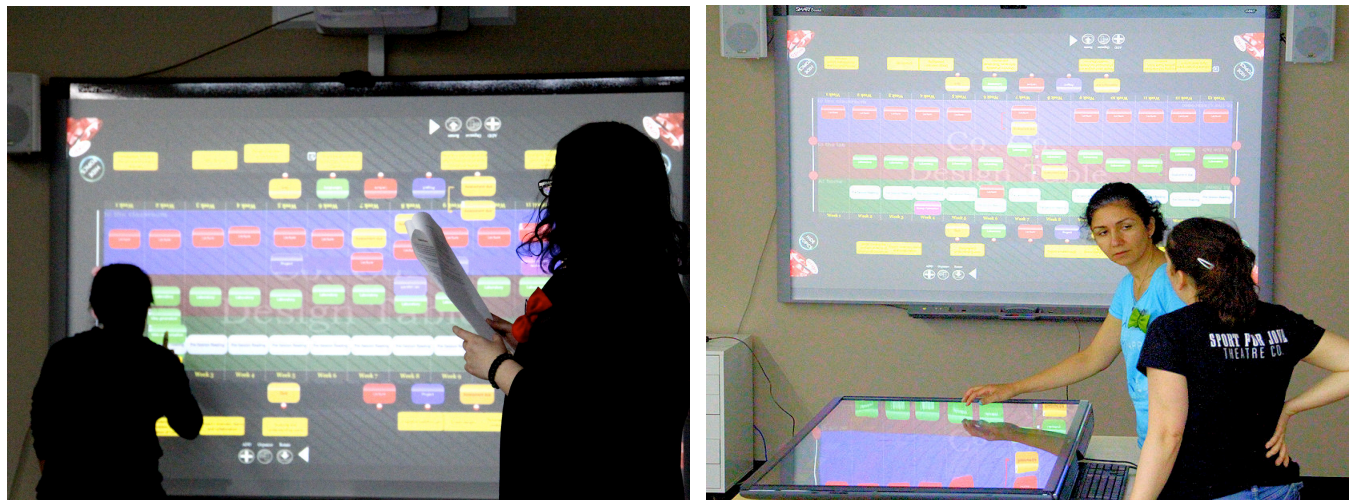

Fig. 12. Usage of the IWB in the EDS. Left: one designer interacting and the second designer looking at the whole design. Group B: looking at the IWB to see the whole design

Questionnaire responses indicate that only a participant in group A found it useful to work on the IWB. The rest of the teacher-designers said that, because of the length of the task, working at the IWB could be tiring. One participant justified this as follows: "it is more comfortable to work at the digital table because your arms are down. You need to do more effort to interact with the IWB because you need to keep the arms lifted all the time". Additionally, "it was not easy to see the whole design while interacting with the IWB". However, as anticipated by the expert users during the workshops in Trial One, seven of the eight teacher-designers said that the interface replicated on both the IWB and the digital table helped them look at the whole design quickly. This suggests that, for this design task, the vertical displays were effective for users to maintain awareness of key information and of the whole design, and they did not need to be interactive to do this.

Another interesting aspect of the group design activity was how each teacher-designer shifted attention between personal work using the tablets and interaction with the shared devices. Fig. 13 depicts three types of observed behaviours: 1 ) the rearrangement of the furniture to work SxS, with each person either holding or sharing a personal device and/or working at the digital table (e.g. group B in Fig. 13, left); 2) designers using their personal devices at each side of the table (e.g. group $\mathrm{C}$ in Fig. 13, centre); or 3 ) designers sharing their personal devices to discuss and gain mutual understanding whilst working F2F (e.g. group D in Fig. 13, right).
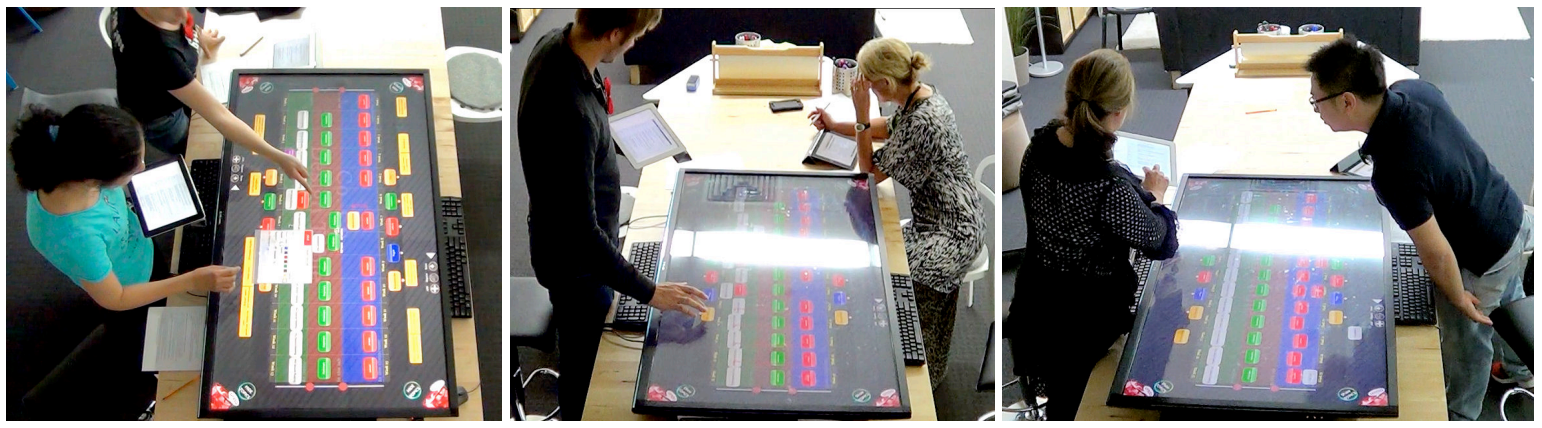
Fig. 13. Tools/space usage and social interactions: Left: Group B working SxS with moments where participants look at the same personal device. Centre: Designers of Group $C$ revising information from the personal devices. Right: Group D sharing a personal device F2F

Most participants mentioned how the portability of the tablets allowed them to more readily accomplish the task. One designer described this as follows: "it was easier to look at the information in the tablet because you can hold it while interacting with the digital table. Also, the resolution of the tablet is very good for reading". All designers indicated that they used the tablets exclusively to consult the CUSP (the information about the course), and they preferred to use the paper-based versions of the task script and the pattern language. For example, a designer indicated that: "It was good to have the [paper] task script on hand rather than switching in between using the tablet. It was easier to navigate through the subject resources on the tablet [the CUSP] and have the instructions on hand so you can immediately find the information quickly". In this way, they preferred to give meaning to the device, correlating the physicality of the material tool with the logical resource (e.g. the tablet to consult the CUSP and the paper for the task instructions).

\subsubsection{Least used tools.}

Teacher-designers were asked why they did not use some of the tools during the interviews. A frequent response was that it would have been more useful if the IWB and the digital table were closer to each other so the transition could have been smoother. One teacher-designer described it as follows: "the tablet could be moved to the area where we were working (the tabletop), but the projections were further. I would be [interacting with] the [vertical] screens a lot more if it they would be next to the digital table". Other teacher-designers suggested that the reason for not sketching on paper or drawing on the writeable wall was that the task did not require discussion of alternative designs: the nature of the task shaping the design activity and tool usage. This dependency was explained by a participant as follows: "if the task would have been different, like brainstorming new design ideas, probably the digital table would have slowed me down and it would have been faster to use paper to sketch them". Additionally, another participant in group D mentioned that they did not use the catalogue of patterns because of the characteristics of the task: "it was easy to figure out what each [pattern] in our design was about". All this can be explained by the nature of the task and the size of the groups. In our early trialling, tasks commonly involved discussions in larger teams formulating early-stage conceptual designs. This kind of work seems more likely to be accompanied by the use of the writeable walls where sketching and inscriptions on the walls were very common. By contrast, in this study, groups were working quickly on a more convergent, downstream design task.

\section{Conclusions and Future Work}

This paper has reported some results from the latest iteration of the EDS, focused on supporting rapid design work by small teams of educational designers - providing them with a set of shared and personal multitouch surface devices. We have learned that it is essential to understand the relationships between tools and space usage within (i) the complex digital and material ecology of tools and resources that collectively constitute the EDS and (ii) the specific social and epistemic situation in which the activity unfolds. The analysis with four pairs of teacher-designers illustrates how the tools and space were used in very different ways, even with the same epistemic and set design. In the actuality of their work, all groups tended to use (and not use) a similar range of tools, but they did so in quite different ways. These differed too from the patterns of tool use observed in the earlier trialling (where the task, group scaffolding and tools available were configured differently). This underlines the close relationships between tasks, tools and social interactions something that needs to be considered in a holistic way when designing and enhancing spaces for collaborative activity, such as this group-based design work. We have learned important lessons about the complexity of face-to-face collaborative educational design. These have the potential to inform further R\&D aimed at supporting both teachers as 'amateur' designers and specially trained 
learning designers - by improving the tools and/or working methods that can make a positive impact on their educational designs. These lessons can be summarised as follows:

1. Collaborative educational design is undoubtedly a complex activity, and it is dangerous to proceed on the basis of simplified normative models of how design should be done. As was illustrated in section 3.3, in addition to acknowledging the varied patterns of tool use, we need to understand the underlying design motivations that drive these decisions. It is the conjunction of social, epistemic and set aspects of the collaborative design activity that ultimately shape (but do not entirely determine) how groups approach a design task. Understanding the complex interaction of these dimensions, and that design intentions are co-configured by the designers during the enactment of their task, can be very valuable for $R \& D$ on better collaborative educational design tools, methods and skillsets.

2. Face-to-face collaboration provides unique benefits to learning design by enhancing designers' mutual awareness and by facilitating fluid group interactions and design processes. Our work is pioneering in the development of tools that can support designers to collaboratively and fluently design courses in a collocated environment. The emergence of other relatively recent examples of online-based collaborative educational design systems namely LdShake (Hernández-Leo, et al., 2014b) and SyncrLD (Derntl, et al., 2013) - suggests that this is an area of R\&D that merits further attention.

3. Each technology (digital or analogue) provides different functionalities for learning designers to perform actions, get access to information or gain awareness about their designs. We observed how different groups and individuals used tools in different ways according to their roles/divisions of labour, epistemic approaches to the design task and individual preferences. For example, the tabletop proved effective to support task work for most designers, whilst the IWB was mostly used as a display to get a different perspective on the group's emerging design. Also, the provision of private display spaces (in the form of tablet devices) allowed some participants to explore relevant information about the course without disrupting others' work, whilst at other moments, they performed similar explorations using the computer projected on the wall.

4. The design of support tools for collocated educational design should carefully consider the whole ecology of multiple devices, resources and design representations within which any new tool(s) will sit. This ecology must be understood as including mundane physical - not just digital - tools and resources, and it must be seen to include all the entities that designers use in their work - not just those that are tightly coupled in the minds of the research team.

Finally, the paper aims to promote discussion of this important area of R\&D in educational technology. Although some of the tools used in the latest iteration of the EDS can still be considered as emergent technologies, we envisage that this paper can be useful for other researchers and developers seeking to provide support to educational designers which already interact with existing ecologies of tools and resources. For example, results of our studies suggest that providing large vertical screens may facilitate the rapid inspection of the whole design. A shared design interface can allow multiple designers to work in parallel while keeping awareness about the design and others' actions. Also, the designers can rapidly adapt their epistemic approach to the design task by combining the different digital and non-digital tools available. Understanding that the set, social and epistemic design components all shape the design activity provides with a more holistic view for designing improved educational design systems instead of focusing only on the development of the design tools. This paper can be seen as one of a series of pieces of research that are needed to bring more usable tools and methods for design for learning into day-to-day use, and to help make teaching a more design-based activity. Our own future work will explore additional options for 
scaffolding designers' activity, such as the use of multiple representations of the same design, support to compare multiple candidate designs and the provision of real-time indicators of pedagogical qualities of design artefacts.

\section{Acknowledgments}

This work was funded by the Australian Research Council (Laureate Fellowship Grant FL100100203) and by the Spanish Ministry (TIN2014-53199-C3-3-R, MDM-2015-0502). Studies presented in this paper were conducted under human ethics protocol number 2012/2794, entitled "Learning, technology and design: architectures for productive networked learning - Using complementary methods of analysis". It was approved by The University of Sydney Human Research Ethics Committee. The most updated participants' information statements and consent forms can be requested by email (Peter.Goodyear@Sydney.edu.au). We are especially grateful to the many users who have given up their time to participate in our studies and their consent to analyse and publish the data collected during their participation.

\section{REFERENCES}

Alexander, C. (1999). The origins of pattern theory: The future of the theory, and the generation of a living world. IEEE Software, 16(5), 71-82.

Badam, S. K., Chandrasegaran, S., Elmqvist, N., \& Ramani, K. (2014). Tracing and sketching performance using blunttipped styli on direct-touch tablets. In Proceedings of the 2014 International Working Conference on Advanced Visual Interfaces, (pp. 193-200). Como, Italy. ACM.

Barker, P. (1987). Author languages for CAL. London: MacMillan.

Botturi, L., \& Stubbs, T. (2008). Handbook of visual languages for instructional design. Hershey, PA: Information Science.

Brasher, A., Conole, G., Cross, S., Weller, M., Clark, P., \& White, J. (2008). CompendiumLD - a tool for effective, efficient and creative learning design. In Proceedings of the 2008 European LAMS Conference: Practical Benefits of Learning Design, (pp. 78-87). Cadiz, Spain.

Britain, S. (2004). A review of learning design: concept, specifications and tools. A report for the JISC E-learning Pedagogy Programme.

Buisine, S., Besacier, G., Aoussat, A., \& Vernier, F. (2012). How do interactive tabletop systems influence collaboration? Computers in Human Behavior, 28(1), 49-59.

Conole, G. (2013). Designing for learning in an open world. New York: Springer.

Cross, S., Galley, R., Brasher, A., \& Weller, M. (2012). OULDI-JISC Project Evaluation Report: the impact of new curriulum design tools and approaches on institutional process and design cultures. OULDI Project (Open University).

Dalziel, J. (2015). Learning Design: Conceptualizing a Framework for Teaching and Learning Online: Routledge.

Derntl, M., Neumann, S., \& Oberhuemer, P. (2011). Propelling Standards-based Sharing and Reuse in Instructional Modeling Communities: The Open Graphical Learning Modeler (OpenGLM). In Proceedings of the 11th IEEE International Conference on Advanced Learning Technologies (ICALT), (pp. 431-435). Athens, GA, USA.

Derntl, M., Nicolaescu, P., Terkik, B., \& Klamma, R. (2013). SynC-LD: Synchronous Collaborative IMS Learning Design Authoring on the Web. In D. Hernández-Leo, T. Ley, R. Klamma \& A. Harrer (Eds.), Scaling up Learning for Sustained Impact, (pp. 540-543). Springer Berlin Heidelberg.

Diggelen, W. v., \& Overdijk, M. (2009). Grounded design: Design patterns as the link between theory and practice. Computers in Human Behavior, 25(5), 1056-1066.

Dillenbourg, P., \& Evans, M. (2011). Interactive tabletops in education. International Journal of Computer-Supported Collaborative Learning, 6(4), 491-514.

Dimitriadis, Y., Goodyear, P., \& Retalis, S. (2009). Using e-learning design patterns to augment learners' experiences. Computers in Human Behavior, 25(5), 997-998.

Eckel, K. (1993). Instruction language: foundations of a strict science of instruction. Englewood Cliffs NJ: Educational Technology Publications.

Ertmer, P., Stepich, D., York, C., Stickman, A., Wu, X., Zurek, S., \& Goktas, Y. (2008). How instructional design experts use knowledge and experience to solve ill-structured problems. Performance Improvement Quarterly, 21(1), 1742.

Evans, M., \& Rick, J. (2014). Supporting Learning with Interactive Surfaces and Spaces. In J. M. Spector, M. D. Merrill, J. Elen \& M. J. Bishop (Eds.), Handbook of Research on Educational Communications and Technology, (pp. 689701). New York: Springer.

Gibbons, A. (2013). An architectural approach to instructional design. New York: Routledge.

Goodyear, P. (1995). Infrastructure for Courseware Engineering. In R. Tennyson \& A. Barron (Eds.), Automating Instructional Design: Computer-Based Development and Delivery Tools, (pp. 11-31). Berlin: Springer Berlin Heidelberg.

Goodyear, P. (1997). Instructional design environments: Methods and tools for the design of complex instructional systems. In S. Dijkstra, N. Seel, F. Schott \& R. Tennyson (Eds.), Instructional design: International perspective, (pp. 83-111). Mahwah NJ: Lawrence Erlbaum Associates. 
Goodyear, P., \& Carvalho, L. (2014). Framing the analysis of learning network architectures. In L. C. P. Goodyear (Ed.), The architecture of productive learning networks, (pp. 48-70). New York, NY: Routledge.

Goodyear, P., \& Dimitriadis, Y. (2013). In medias res: reframing design for learning. Research in Learning Technology, 21, 1-13.

Goodyear, P., \& Retalis, S. (2010a). Learning, technology and design. In P. Goodyear \& S. Retalis (Eds.), Technologyenhanced learning: design patterns and pattern languages, (pp. 1-28). Rotterdam: Sense Publishers.

Goodyear, P., \& Retalis, S. (2010b). Technology-enhanced learning: design patterns and pattern languages. Rotterdam: Sense Publishers.

Haller, M., Leitner, J., Seifried, T., Wallace, J. R., Scott, S. D., Richter, C., Brandl, P., Gokcezade, A., \& Hunter, S. (2010). The NiCE Discussion Room: Integrating Paper and Digital Media to Support Co-Located Group Meetings. In Proceedings of the SIGCHI Conference on Human Factors in Computing Systems, (pp. 609-618). Atlanta, Georgia, USA. ACM.

Hernández-Leo, D., Asensio-Pérez, J., Derntl, M., Prieto, L., \& Chacón, J. (2014a). ILDE: Community Environment for Conceptualizing, Authoring and Deploying Learning Activities. In C. Rensing, S. de Freitas, T. Ley \& P. MuñozMerino (Eds.), Open Learning and Teaching in Educational Communities, (pp. 490-493). Springer International Publishing.

Hernández-Leo, D., Moreno, P., Chacón, J., \& Blat, J. (2014b). LdShake support for team-based learning design. Computers in Human Behavior, 37, 402-412.

Hernández-Leo, D., Villasclaras-Fernández, E., Asensio-Pérez, J., \& Dimitriadis, Y. (2007). Diagrams of learning flow patterns' solutions as visual representations of refinable IMS Learning Design templates. Handbook of Visual Languages for Instructional Design: Theories and Practices. IGI Global.

Hornecker, E., Marshall, P., Dalton, N. S., \& Rogers, Y. (2008). Collaboration and interference: awareness with mice or touch input. In Proceedings of the International Conference on Computer Supported Cooperative Work 2008 (CSCW 2008), (pp. 167-176). San Diego, CA, USA. New York: ACM.

Huizinga, T., Handelzalts, A., Nieveen, N., \& Voogt, J. M. (2013). Teacher involvement in curriculum design: need for support to enhance teachers' design expertise. Journal of Curriculum Studies, 46(1), 33-57.

Kaptelinin, V. (2005). The object of activity: Making sense of the sense-maker. Mind, culture, and activity, 12(1), 4-18.

Kharrufa, A., Martinez-Maldonado, R., Kay, J., \& Olivier, P. (2013). Extending tabletop application design to the classroom. In Proceedings of the International Conference on Interactive Tabletops and Surfaces, (pp. 115-124). St Andrews, UK. New York: ACM.

Kirschner, P., Carr, C., van Merriënboer, J., \& Sloep, P. (2002). How Expert Designers Design. Performance Improvement Quarterly, 15(4), 86-104.

Koper, R., \& Tattersall, C. (2005). Learning design: a handbook on modelling and delivering networked education and training. Berlin: Springer.

Koutsabasis, P., Vosinakis, S., Malisova, K., \& Paparounas, N. (2012). On the value of virtual worlds for collaborative design. Design Studies, 33(4), 357-390.

Laurillard, D. (2012). Teaching as a design science: Building pedagogical patterns for learning and technology. New Year: Routledge.

Laurillard, D., Charlton, P., Craft, B., Dimakopoulos, D., Ljubojevic, D., Magoulas, G., Masterman, E., Pujadas, R., Whitley, E. A., \& Whittlestone, K. (2013). A constructionist learning environment for teachers to model learning designs. Journal of Computer Assisted Learning, 29(1), 15-30.

Li, W. D., Lu, W. F., Fuh, J. Y. H., \& Wong, Y. S. (2005). Collaborative computer-aided design—research and development status. Computer-Aided Design, 37(9), 931-940.

Lu, J., Lajoie, S. P., \& Wiseman, J. (2010). Scaffolding problem-based learning with CSCL tools. International Journal of Computer-Supported Collaborative Learning, 5(3), 283-298.

Martinez-Maldonado, R., Collins, A., Kay, J., \& Yacef, K. (2011). Who did what? who said that? Collaid: an environment for capturing traces of collaborative learning at the tabletop. In Proceedings of the 6th ACM International Conference on Interactive Tabletops and Surfaces (pp. 172-181). Kobe, Japan. New York: ACM.

Martinez-Maldonado, R., \& Goodyear, P. (2016). CoCoDeS: multi-device support for collocated collaborative learning design. In Proceedings of the 28th Australian Conference on Computer-Human Interaction, (pp. 185-194). Launceston, Tasmania, Australia. New York: ACM.

Martinez-Maldonado, R., Goodyear, P., Dimitriadis, Y., Thompson, K., Carvalho, L., Prieto, L. P., \& Parisio, M. (2015). Learning about Collaborative Design for Learning in a Multi-Surface Design Studio. In Proceedings of the International Conference on Computer-Supported Collaborative Learning, (pp. 174-181). Gothenburg, Sweden. New York: Springer.

Martinez-Maldonado, R., Goodyear, P., Kay, J., Thompson, K., \& Carvalho, L. (2016). An Actionable Approach to Understand Group Experience in Complex, Multi-surface Spaces. In Proceedings of the Conference on Human Factors in Computing Systems (CHI' 16), (pp. 2062-2074). Santa Clara, California, USA. New York: ACM.

McAndrew, P., Goodyear, P., \& Dalziel, J. (2006). Patterns, designs and activities: unifying descriptions of learning structures. International Journal of Learning Technology, 2(2), 216-242.

McComb, C., Cagan, J., \& Kotovsky, K. (2015). Rolling with the punches: An examination of team performance in a design task subject to drastic changes. Design Studies, 36, 99-121.

Mitchell, W. J. (1977). Computer-aided architectural design New York: Petrocelli/Charter.

Mor, Y., \& Mogilevsky, O. (2013). The learning design studio: collaborative design inquiry as teachers' professional development. Research in Learning Technology, 21(22054).

Müller-Tomfelde, C., \& Fjeld, M. (2010). A Short History of Tabletop Research, Technologies, and Products. In C. MüllerTomfelde (Ed.), Tabletops - Horizontal Interactive Displays, (pp. 1-24). Springer London.

Nicolaescu, P., Derntl, M., \& Klamma, R. (2013). Browser-based collaborative modeling in near real-time. In Proceedings of the 9th International Conference Conference on Collaborative Computing: Networking, Applications and Worksharing (Collaboratecom), (pp. 335-344). Austin, US. IEEE.

Norman, K. L., Weldon, L. J., \& Shneiderman, B. (1986). Cognitive layouts of windows and multiple screens for user interfaces. International Journal of Man-Machine Studies, 25(2), 229-248. 
Okdie, B. M., Guadagno, R. E., Bernieri, F. J., Geers, A. L., \& McLarney-Vesotski, A. R. (2011). Getting to know you: Face-to-face versus online interactions. Computers in Human Behavior, 27(1), 153-159.

Oleksik, G., Milic-Frayling, N., \& Jones, R. (2014). Touch and gesture: mediating content display, inscriptions, and gestures across multiple devices. Personal and Ubiquitous Computing, 18(5), 1243-1257.

Olson, J. S., Teasley, S., Covi, L., \& Olson, G. (2002). The (currently) unique advantages of collocated work. In P. J. Hinds \& S. Kiesler (Eds.), Distributed work: New research on working across distance using technology (pp. 113-136). Cambridge, MA: MIT Press.

Paquette, G. (2013). Technology-based instructional design: evolution and major trends. In J. M. Spector, D. Merrill, J. Elen \& M. Bishop (Eds.), Handbook of research on educational communications and technology (pp. 661-667). New York: Springer.

Pirolli, P. (1991). Computer-aided instructional design systems. In H. Burns, J. Parlett \& C. Redfield (Eds.), Intelligent Tutoring Systems: Evolution in Design (pp. 105-125). Hillsdale New Jersey: Lawrence Erlbaum Associates.

Pirolli, P., \& Russell, D. (1990). The Instructional Design Environment: technology to support design problem solving. Instructional Science, 19(2), 121-144.

Prieto, L. P., Dimitriadis, Y., Craft, B., Derntl, M., Émin, V., Katsamani, M., Laurillard, D., Masterman, E., Retalis, S., \& Villasclaras, E. (2013). Learning design Rashomon II: exploring one lesson through multiple tools. Research in Learning Technology, 21(2013).

Prieto, L. P., Tchounikine, P., Asensio-Pérez, J. I., Sobreira, P., \& Dimitriadis, Y. (2014). Exploring teachers' perceptions on different CSCL script editing tools. Computers \& Education, 78(September 2014), 383-396.

Rogers, Y., Lim, Y.-k., Hazlewood, W. R., \& Marshall, P. (2009). Equal Opportunities: Do Shareable Interfaces Promote More Group Participation Than Single User Displays? Human-Computer Interaction, 24(1-2), 79-116.

Rowland, G. (1992). What Do Instructional Designers Actually Do? An Initial Investigation of Expert Practice. Performance Improvement Quarterly, 5(2), 65-86.

Schmitt, L., Buisine, S., Chaboissier, J., Aoussat, A., \& Vernier, F. (2012). Dynamic tabletop interfaces for increasing creativity. Computers in Human Behavior, 28(5), 1892-1901.

Scott, S. D., Grant, K. D., \& Mandryk, R. L. (2003). System guidelines for co-located, collaborative work on a tabletop display. In Proceedings of the European Conference on Computer Supported Cooperative Work 2003 (ECCSCW 2003), (pp. 159-178). Helsinki, Finland. Norwell, MA, USA: Kluwer Academic Publishers.

Shneiderman, B. (1996). The eyes have it: A task by data type taxonomy for information visualizations. In Proceedings of the IEEE Symposium on Visual Languages, 1996, (pp. 336-343). Boulder, CO. IEEE.

Sobreira, P., \& Tchounikine, P. (2012). A model for flexibly editing CSCL scripts. International Journal of ComputerSupported Collaborative Learning, 7(4), 567-592.

Strijbos, J.-W., Kirschner, P., \& Martens, R. (2004). What we know about CSCL: and implementing it in higher education. Boston: Kluwer.

Tennyson, R. D., \& Barron, A. E. (2012). Automating instructional design: Computer-based development and delivery tools (Vol. 140): Springer Science \& Business Media.

Tessmer, M., \& Wedman, J. (1995). Context-Sensitive Instructional Design Models: A Response to Design Research, Studies, and Criticism. Performance Improvement Quarterly, 8(3), 38-54.

Thompson, K. (2015). The effects on the processes of learning and design of scaffolding, design, roles, and tool use in a collaborative design task using multimodal learning analytics. In Proceedings of the Computer Supported Collaborative Learning (CSCL 2015), (pp. 803-804). Goteborg, Sweden. ISLS.

Thompson, K., Ashe, D., Carvalho, L., Goodyear, P., Kelly, N., \& Parisio, M. (2013a). Processing and visualizing data in complex learning environments. American Behavioral Scientist, 57(10), 1401-1420.

Thompson, K., Ashe, D., Wardak, D., Yeoman, P., \& Parisio, M. (2013b). Identification of patterns of tool use and sketching practices in a learning by design task. In Proceedings of the International Conference on ComputerSupported Collaborative Learning (CSCL 2013), (pp. 478-485). Madison, WI, USA. ISLS.

Thompson, K., Ashe, D., Yeoman, P., \& Parisio, M. (2013c). Phases of design: Following idea development and patterns of collaborative discussion in a learning by design project. . In Proceedings of the International Conference on Computer-Supported Collaborative Learning (CSCL 2013), (pp. 494-501). Madison, WI, USA. ISLS.

van Merriënboer, J. G., \& Martens, R. (2002). Computer-based tools for instructional design: An introduction to the special issue. Educational Technology Research and Development, 50(4), 5-9.

Vasiliou, C., Ioannou, A., \& Zaphiris, P. (2014). Understanding collaborative learning activities in an information ecology: A distributed cognition account. Computers in Human Behavior, 41, 544-553.

Villasclaras-Fernández, E., Hernández-Leo, D., Asensio-Pérez, J. I., \& Dimitriadis, Y. (2013). Web Collage: An implementation of support for assessment design in CSCL macro-scripts. Computers \& Education, 67(September 2013), 79-97.

Wardak, D. (2014). Traces on the Walls and Traces in the Air: Inscriptions and Gestures in Educational Design Team Meetings. PhD dissertation. The University of Sydney: Faculty of Education and Social Work.

Wigdor, D., Jiang, H., Forlines, C., Borkin, M., \& Shen, C. (2009). WeSpace: the design development and deployment of a walk-up and share multi-surface visual collaboration system. In Proceedings of the ACM SIGCHI Conference on Human Factors in Computing Systems, (pp. 1237-1246). Boston, MA. New York: ACM.

Wineman, J., Hwang, Y., Kabo, F., Owen-Smith, J., \& Davis, G. F. (2014). Spatial layout, social structure, and innovation in organizations. Environment and Planning B: Planning and Design, 41(6), 1100-1112. 